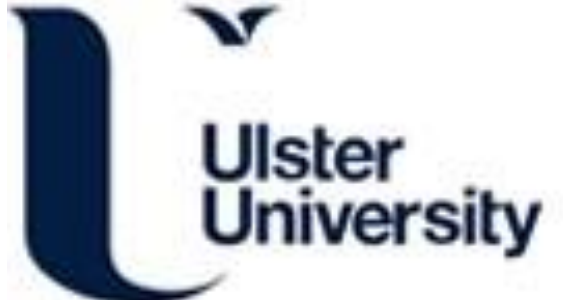

\section{Step-wise Land-class Elimination Approach for extracting mixed-type built-up areas of Kolkata megacity}

Khan, A., Chatterjee, S., Akbari, H., Bhatti, S. S., Dinda, A., Mitra, C., Hong, H., \& Doan, Q. V. (2019). Step-wise Land-class Elimination Approach for extracting mixed-type built-up areas of Kolkata megacity. Geocarto International, 34(5), 504-527. https://doi.org/10.1080/10106049.2017.1408704

Link to publication record in Ulster University Research Portal

\section{Published in:}

Geocarto International

Publication Status:

Published (in print/issue): 16/04/2019

DOI:

10.1080/10106049.2017.1408704

\section{Document Version}

Author Accepted version

\section{General rights}

Copyright for the publications made accessible via Ulster University's Research Portal is retained by the author(s) and / or other copyright owners and it is a condition of accessing these publications that users recognise and abide by the legal requirements associated with these rights.

\section{Take down policy}

The Research Portal is Ulster University's institutional repository that provides access to Ulster's research outputs. Every effort has been made to ensure that content in the Research Portal does not infringe any person's rights, or applicable UK laws. If you discover content in the Research Portal that you believe breaches copyright or violates any law, please contact pure-support@ulster.ac.uk. 


\title{
Step-wise Land-class Elimination Approach for extracting mixed-type built-up areas of Kolkata megacity
}

\author{
Ansar Khan, Soumendu Chatterjee, Hashem Akbari, Saad Saleem Bhatti, \\ Apurba Dinda, Chandana Mitra, Haoyuan Hong \& Quang Van Doan
}

To cite this article: Ansar Khan, Soumendu Chatterjee, Hashem Akbari, Saad Saleem Bhatti, Apurba Dinda, Chandana Mitra, Haoyuan Hong \& Quang Van Doan (2017): Step-wise Land-class Elimination Approach for extracting mixed-type built-up areas of Kolkata megacity , Geocarto International, DOI: 10.1080/10106049.2017.1408704

To link to this article: https://doi.org/10.1080/10106049.2017.1408704

Accepted author version posted online: 23

Nov 2017.

Submit your article to this journal $\pi$

View related articles ¿

View Crossmark data $₫$ 
Publisher: Taylor \& Francis

Journal: Geocarto International

DOI: http://doi.org/10.1080/10106049.2017.1408704

\title{
Step-wise Land-class Elimination Approach for extracting mixed-type built-up areas of Kolkata megacity
}

\author{
Ansar Khana,", Soumendu Chatterjeeb, Hashem Akbaric, Saad Saleem Bhattid, Apurba \\ Dinda $^{\mathrm{e}}$, Chandana Mitraf, Haoyuan Hongs, Quang Van Doan ${ }^{\mathrm{h}}$
}

\author{
Ansar Khan \\ Assistant Professor \\ Department of Geography, Lalbaba College, Howrah, India \\ Email: khanansargeo@gmail.com \\ Soumendu Chatterjee \\ Professor and Head \\ Department of Geography, Presidency University, Kolkata, India \\ Email: soumendu.geog@presiuniv.ac.in
}

\section{Hashem Akbari}

Professor

Heat Island Group, Building, Civil and Enyironmental Engineering, Concordia University,

Montreal, Canada

Email: hakbari@encs.concordia.ca

Saad Saleem Bhatti

Research Associate

Department of Geography and Planning, School of Environmental Sciences, University of Liverpool, Liverpool, United Kingdom

Email: dearsaad@gmail.com

Apurba Dinda

Research Assistant

Department of Geography and Environment Management, Vidyasagar University, Midnapore, India Email: apurbadinda0@gmail.com

\section{Chandana Mitra}

Associate Professor

Department of Geosciences, Auburn University, Auburn, Alabama

Email: czm0033@auburn.edu

\section{Haoyuan Hong}

Research Scientist

Jiangxi Provincial Meteorological Observatory, Jiangxi Meteorological Bureau, Nanchang, China

Email: honghaoyuan@qq.com 


\title{
Quang Van Doan
}

Research Scientist

Center for Computational Sciences, University of Tsukuba, Tsukuba, Japan

Email: doanquangvan@gmail.com

${ }^{*}$ Corresponding author:

Department of Geography, Lalbaba College, Howrah, India

Email: khanansargeo@gmail.com

\section{Step-wise Land-class Elimination Approach for extracting mixed-type built-up areas of Kolkata megacity}

\begin{abstract}
The extraction of urban built-up areas is an important aspect of urban planning and understanding the complex drivers and biophysical mechanism of urban climate processes. However, built-up area extraction using Landsat data is a challenging task due to spatiotemporal dynamics and spatially intermixed nature of Land Use and Land Cover (LULC) in the cities of the developing countries, particularly in tropics. In the light of advantages and drawbacks of the Normalized Difference Built-up Index (NDBI) and Built-up Area Extraction Method (BAEM), a new and simple method i.e. Step-wise Land-class Elimination Approach (SLEA) is proposed for rapid and accurate mapping of urban built-up areas without depending exclusively on the band specific normalized indices, in order to pursue a more generalized approach. It combines the use of a single band layer, Normalized Difference Vegetation Index (NDVI) image and another binary image obtained through Logit model. Based on the spectral designation of the satellite image in use, a particular band is chosen for identification of water pixels. The Double-window Flexible Pace Search (DFPS) approach is employed for finding the optimum threshold value that segments the selected band image into water and non-water categories- the water pixels are then eliminated from the original image.
\end{abstract}


The vegetation pixels are similarly identified using the NDVI image and eliminated. The residual pixels left after elimination of water and vegetation categories belong either to the built-up areas or to bare land categories. Logit model is used for separation of the built-up areas from bare lands. The effectiveness of this method was tested through the mapping of built-up areas of the Kolkata Metropolitan Area (KMA), India from Thematic Mapper (TM) images of 2000, 2005 and 2010, and Operational Land Imager (OLI) image of 2015. Results of the proposed SLEA were $95.33 \%$ accurate on the whole, while those derived by the NDBI and BAEM approaches returned an overall accuracy of $83.67 \%$ and $89.33 \%$, respectively. Comparisons of the results obtained using this method with those obtained from NDBI and BAEM approaches demonstrate that the proposed approach is quite reliable. The SLEA generates new patterns of evidence and hypotheses for built-up areas extraction research, providing an integral link with statistical science and encouraging trans-disciplinary collaborations to build robust knowledge and problem solving capacity in urban areas. It is also brings landscape architecture, urban and regional planning, landscape and ecological engineering, and other practice-oriented fields to bear in processes for identifying problems and analyzing, synthesizing, and evaluating desirable alternatives for urban change. This method produced very accurate results in a more efficient manner compared to the earlier built-up area extraction approaches for the landscape and urban planning.

\section{Keywords:}

Double-window flexible pace search; Kolkata metropolitan area; Logit model; Spatially intermixed LULC; Step-wise land-class elimination 


\section{Introduction}

Remote sensing techniques for the extraction of urban land use information have drawn immense research attention during the last three decades. Satellite Remote Sensing (SRS) images with increasingly improved optical quality are now invaluable resources for discrimination of land cover types within cities at appreciably finer levels of accuracy. Automatic and semi-automatic methods of detecting urban features from images have evolved with enhanced details of information captured by more powerful sensors. These imageries, being available historically, allow determination of the dynamic nature of urbanization, characterized by alteration of the natural land areas into unreceptive built-up areas (DeFries, 2008, Mushore et al., 2017). Apart from such modifications in the urban core, urban areas encroach on to the surrounding natural lands such as agricultural fields, forestlands and wetlands as peri-urban dynamic processes (Xu, 2008; Estoque \& Murayama, 2015). Remote sensing based (timely and cost-effective) mapping of built-up areas facilitates subsequent urban analysis and modeling of the urban morphology, urban hydrology, urban ecology and urban climate. The significance of expanding built-up areas in intensifying Urban Heat Island (UHI) phenomena cannot be ignored (Stone, 2007; Xu, 2008; Gibril et al., 2017). Apropos recent global warming and climate change concerns, it has been suggested that the warming trends observed at continental weather stations could be partly influenced by rapid urbanization and local UHIs (Jones et al., 2008; Parker, 2010; Khan et al., 2015). As urbanization is an alarming and accelerating phenomenon across the world, especially in developing countries like India, the investigation of UHI effects has accrued momentum (DeFries \& Pandey, 2010; Liu \& Yang, 2015).

The study of spatial expansion of urban built-up areas always needs accurate information on the size, shape and spatial structure of built-up features (Xu, 2008; Wang et al., 2015). Therefore, a scientific and robust technique is required to quickly retrieve such 
information, and its success depends on the availability of spatio-temporal data. Fortunately, SRS technology offers considerable pledge to meet these requirements. SRS data are useful for monitoring the growth of urban built-up areas as well as their sprawling effects due to their ability to provide varied spatial and temporal resolutions, consistent and repetitive measurements and synoptic views of Land Use and Land Cover (LULC) (Guindon et al., 2004; Xu, 2008; Bhatta, 2009; Griffiths et al., 2010; Bouzekri et al., 2015).Early researchers have made use of SRS imagery to address urban and suburban problems (Jacquin et al., 2008). Several techniques have been formulated, applied and evaluated to achieve desirable level of accuracy in automated mapping of urban LULC. These techniques can be broadly grouped into three categories:(a) pixel-based classification (Jensen, 1986; Gong et al., 1992; Casals-Carrasco et al., 2000; Zhou and Robson, 2001; Dean \& Smith, 2003);(b) object-based classification (Giada et al., 2003; Guindon et al., 2004; Gao et al., 2006; Qian et al., 2007; Cleve et al., 2008); and (c) application of spectral indices such as Normalized Difference Built-up Index (NDBI) (Zha et al., 2003; Zhang et al., 2005). Pixel-based approach is still considered efficient for classificatory purposes when employed on multi-band imageries of medium resolution (Adam et al., 2016). Exploring the advantages of the unique spectral signature of built-up areas and other LULC of Thematic Mapper (TM) images, Zha et al. (2003) formulated NDBI for automatic extraction of built-up areas. The method involves simple arithmetic manipulation of re-coded Normalized Difference Vegetation Index (NDVI) and NDBI binary images which indicated vegetation and built-up areas, respectively for pixel value $=1$. Reportedly, this process is unable to separate urban built-up areas from bare lands (Zha et al., 2003; Zhai et al., 2015). It has been suggested that the universality of the approach needs to be tested in other geographic areas because spectral response patterns of vegetation and other LULC classes are actually more complicated than were assumed (Zha et al., 2003; Bhatti \&Tripathi, 2014; Mushore et al., 2017). The problem is more acute in case of 
old cities like Kolkata, where mixed urban development has continued throughout its history of urbanization. As a refinement of the original method, He et al. (2010) suggested that continuous images of NDBI and NDVI be used, not the binary images and then a final separation of built-up areas on the basis of an optimal threshold value determined adopting Double-window Flexible Pace Search (DFPS) technique (Chen et al., 2003). This modified approach has been demonstrated to be comparatively better than the customary NDBI approach in terms of overall accuracy (He et al., 2010; Bhatti \& Tripathi, 2014; Lu et al., $2015)$.

NDBI has been widely used for the mapping of urban built-up areas from TM images. Afterwards, Bhatti \& Tripathi (2014) tested the applicability of this approach on Landsat-8 Operational Land Imager (OLI) and proposed a new Built-up Area Extraction Method (BAEM) for improving the performance of index-based separation of built-up pixels. This new approach considers Principal Component Analysis (PCA) as a method to ensure optimal utilization of information in image data and accordingly uses the first Principal Component (PC) image of the highly correlated bands in Landsat-8 OLI imagery to replace the spectrally equivalent TM band in the original formula for computing NDBI. Similarly, strategies for calculating NDVI and Normalized Difference Water Index (NDWI) were modified by substitution of TM bands with corresponding OLI bands. Finally, the BAEM image was obtained by simple arithmetic operation on modified NDBI, modified NDVI and modified NDBI images of continuous type (Bhatti \& Tripathi, 2014). The threshold value for the extraction of built-up areas from this BAEM image was then determined through the DFPS technique. The BAEM subsequently brought a noticeable improvement in NDBI approach to make it commensurate with the Landsat-8 images and also revealed a higher overall accuracy than modified NDBI method (Ke et al., 2015; Piyoosh \& Ghosh, 2017). 
In spite of all these efforts, the accuracy in extraction of built-up area from satellite images still lies below $80 \%$ and currently available methods fail to completely separate builtup areas from bare lands (Pant et al., 2016). Results from a lot of studies revealed that there has not been a single technique to classify the built-up areas but one combines the intrinsic aspect of two or more techniques in order to build a hybrid approach to improve the extraction accuracy of urban LULC.Hence, a satisfactory technique with justifiable approach is necessary. The major challenges encountered while analyzing raster data in wavelength domain arehigh probability of misclassification due to mixed pixel problem (Lo \& Choi, 2004) and the juxtaposition of discrete and continuous features in an extremely heterogeneous urban landscape (Aplin, 2006). Moreover, Very High Resolution (VHR) images are prohibitively expensive for urban agencies and researchers to be used in real applications. One way of handling these difficulties is to develop a regression model based on digital number (DN) values of sample pixels from those bands which can significantly distinguish a feature class from the rest, and to apply such models on medium resolution images.

In light of the original NDBI and BAEM approach's recompense and drawback, a new and simple method is proposed here for the rapid and accurate mapping of urban built-up areas without depending exclusively on the band specific normalized indices, in order to pursue a more generalized approach befitting both TM and OLI images. The indifference in the spectral response of built-up areas and bare soils to thermal bands makes the separation of these two land categories difficult, particularly in tropical areas. Encountering this problem for the city of Kolkata, the proposed method excludes the thermal bands in extraction of built-up areas. This new approach, called Step-wise Land-class Elimination Approach (SLEA) combines the use of a single band layer, an NDVI image and another binary image obtained through Logit model. Based on the spectral designation of the satellite image, a 
particular band is chosen for identification of water pixels. The DFPS approach is employed for finding the optimum threshold value that segments the selected band image into water and non-water categories - the water pixels are then eliminated from the original image in use. The vegetation pixels are similarly identified using the NDVI image and eliminated. The residual pixels left after eliminating water and vegetation categories are assumed to be the built-up and bare land categories, and thus need to be separated. For extracting built-up areas, Logit model is used to select the probable image bands appropriate for recognizing the land characters. It allows, after coefficient optimization, to model the link between a set of explanatory bands and a dichotomous dependent output which, at a given probability, reveals if a pixel belongs to the built-up class or not. The mapping is accomplished through recoding of the final image.This method, importantly, does not involve much of subjective human intervention in the mapping process. The effectiveness of this method was tested through the mapping of built-up areas in the Kolkata metropolis of India from TM images of 2000, 2005 and 2010, and OLI image of 2015. Comparison of the results obtained using this method with those interpreted manually demonstrates that the proposed approach is quite reliable. This method produced very accurate results in a more efficient manner compared to the earlier built-up area extraction approaches.

The past study revealed that most of the studies developed spectral indices for rapid extraction of built-up areas from various types of satellite images based on specific image data (Sameen \& Pradhan, 2016). Therefore, it is needed to improve band specific approach for Landsat satellite images, which is not examined in previous study. In addition, inspection further advanced and robust methods are prerequisite to be involved in the improvement of spectral response for tropical environment. Therefore, this study proposes a novel spectral land-class elimination approach for rapid extraction of built-up areas from Landsat images. For this, researchers' use of a single band layer, an NDVI image and another binary image 
obtained through Logit model. This approach offers paramount solution for numerous problems including the selection of relevant bands and determining the best combination of spectral bands for the elimination of final land-class in tropical city.

\section{Study Area}

The present study of built-up area extraction was conducted on Kolkata Metropolitan Area (KMA), delimited by the latitudes of $22.01^{\circ} \mathrm{N}$ and $23.08^{\circ} \mathrm{N}$, and the longitudes of $88.03^{\circ} \mathrm{E}$ and $88.45^{\circ} \mathrm{E}$, developed mainly along the banks of the river Hugli about $150 \mathrm{~km}$ to the north of the Bay of Bengal (BoB), right over the Gangetic delta plains (Fig. 1). This is one of the leading urbanized areas in India, as well as of the urban world characterized by swift urbanization and associated spatio-temporal variation in biophysical processes. KMA, the largest urban agglomeration in eastern India, extending over $1851.41 \mathrm{~km}^{2}$ comprises 4 municipal corporations, 39 municipalities, and 1 cantonment, and parts of 24 panchayat samiti (rural local governments at the intermediate level in administrative structure of India)(Census of India, 2011). Kolkata is the most important commercial and industrialized centre of east and northeast Indian hinterland, and it holds essential manufacturing and transportation infrastructure (Nath et al., 2015). The population of core Kolkata was 1.5 million in 1901, 11 million in 1991 and an exceptional 14.2 million in 2011 (Census of India, 2011). In some parts of the KMA, the population density exceeds 10,000 persons $/ \mathrm{km}^{2}$. Owing to the huge demand of land for housing the tremendously growing population, accommodating the ever increasing vehicular traffic and facilitating the booming trade and commerce, the city has intensified the use of land and, at the same time, has also intruded into the adjacent natural back swamp and marshy lands to the east. Planned development, particularly in the Salt Lake City and New Town-Rajarhat areas, and spontaneous haphazard growth in inner city areas characterize the urbanization process in Kolkata. Both filling up of 
widespread natural areas in the former instance, and densification of landuse in the later, are adding to the intensity of the heat island effect in Kolkata at the city scale as well as at the neighbourhood level (Stone, 2007; Bhatta et al., 2009; Khan, \& Chatterjee, 2016). More than $80 \%$ of land in the city core is built-up with high-rise residential buildings, overcrowded commercial areas, hospitals and different other institutions (Nandy, 2007). Aesthetically, the city exhibits wide variations from leafy residential areas like Alipore and Rajarhat to 'grey' areas of Binoy-Badal-Dinesh (BBD) Bag (erstwhile Dalhousie Square). Kolkata's business district shows unmistakable signs of haphazard developments mirroring the reality in other big cities in the country.

$<$ Fig. 1 $>$

\section{Methods and materials}

\subsection{Pre-processing of imagery}

Images from two different sensors of Landsat satellite series were used for delineation of built-up areas in Kolkata metropolis i.e. TM of Landsat-5 and OLI and Thermal Infrared Sensor (TIRS) of Landsat-8 (Table 1). All multi-temporal images were pre-processed in ERDAS 2014 and subsequent analysis was carried out in ArcGIS 10.1 software. Only the cloud-free images were selected for this study, hence no atmospheric correction was required (Deng \& Wu, 2013; Bhatti \& Tripathi, 2014). For the purpose of comparing three different approaches (NDBI, BAEM and SLEA), the entire set of bands of all the selected images required necessary pre-processing, though the proposed SLEA does not include the thermal bands. Initially, a rectangular area encompassing the KMA was clipped from the original images in order to avoid null pixels at the processing stage. Careful observation of the standard False Colour Composite (FCC) band combination helped to distinguish diverse types of LULC (Zha et al., 2003). Field survey and unsupervised classification of the images with variable number of classes revealed that the area comprises four principal land-class 
types namely water bodies, vegetated areas (including other green coverage), bare lands and built-up areas. TM band 4 and 5 were most pertinent for discerning the urban built-up areas from other LULC types (Zha et al., 2003; He et al., 2010; Bhatti \& Tripathi, 2014). In case of OLI bands, the spectral ranges differ from those of TM, so, it was necessary to examine the spectral signatures of built-up areas in different bands of OLI bands before developing any suitable method for built-up areas extraction (Bhatti \& Tripathi, 2014). For this, the spectral signatures associated with built-up, vegetation and water areas in different bands of TM and OLI were examined. The plots for the Digital Number (DN) values of 20 sample pixels each from every land class typein: (a) optical bands 1-5 and 7 of Landsat-5 TMand; (b) optical bands 2-7 of Landsat-8 OLI are shown in Fig. 2. It reveals that vegetation show higher spectral reflectance than other LULC classes in the TM Band 4 and OLI band 5. Therefore, subtraction of band 3 from band 4 (for TM images) and subtraction of band 4 from band 5 (for OLI images) produce positive values for vegetation pixels (Zha et al., 2003; Bhatti \& Tripathi, 2014).

$<$ Table 1> Satellite data used in the study.

$<$ Fig. 2>

The multi-temporal sub-set (clipped) images have been geometrically rectified using 200 Ground Control Points (GCPs). The Root Mean Square Error (RMSE) at all GCPs ranged from $0.25-0.86$ pixels, which is acceptable and quite suitable for further processing (Gibson, 2000; Askne et al., 2003). Afterwards, the original images were projected into Universal Transverse Mercator (UTM) system and resampled to the same spatial resolution using nearest neighbour technique (Zha et al., 2003). In case of Landsat 8 OLI/TIRS, digital DNs of optical bands 2-8 were converted to Top of Atmosphere (ToA) reflectance and DNs of thermal bands 10 and 11 were first converted to ToA reflectance and subsequently processed to obtain at-satellite brightness temperature in ${ }^{\circ} \mathrm{C}$ (USGS, 2013; Bhatti \& Tripathi, 
2014). The working formulae for translating the $\mathrm{DN}$ values into ToA reflectance and atsatellite brightness are available in the Landsat- 8 data user handbook (USGS, 2013). The optical bands 2-7 (except the panchromatic band 8) were then stacked into a multi-band image file and similarly, the thermal bands 10 and 11 were stacked into another image file. The spectrally rectified optical stack (bands 2-7, spatial resolution 30m) was then combined with high-resolution panchromatic layer (band 8 , spatial resolution $15 \mathrm{~m}$ ) by using the High Pass Filter (HPF) resolution merge function to obtain an output (spatial resolution $15 \mathrm{~m}$ ) with greater detail (Gangkofner et al., 2008: Bhatti and Tripathi, 2014). The values of the parameters, used in this image sharpening process, were set accordingly. The Fig. 3 compares the original image with spatially enhanced image for a sample area of the Salt Lake City in Kolkata. The thermal bands 10 and 11 were resampled to a spatial resolution of $15 \mathrm{~m}$, in order to make them compatible with the spectral bands.

$<$ Fig. 3 $>$

In case of Landsat-5 TM images for 2000, 2005 and 2010, the above resolution merging was not possible as the sensor does not deliver any panchromatic band of higher resolution. Therefore, after re-projection and re-sampling, the bands 1-5 and 7 (exceptthe thermal band 6) were directly stacked into a multi-band image file for further processing.

\subsection{Built up area extraction}

The proposed method for extraction of built-up areas using TM and OLI imagery considers elimination, in phases, of the LULC categories, and retains the built-up areas finally (Fig. 4). Starting with all the component LULC classes, water and vegetation pixels were detected and excluded, and the resultant image was then used as the input to a Logit model for separation of built-up pixels from the bare land pixels.

\subsubsection{Step 1: Elimination of water class}


The most significant spectral character of water is energy absorption at the Shortwave Infrared (SWIR) wavelengths. A single band density slices classification of Landsat-5 images using the TM band $5(1.55-1.75 \mu \mathrm{m})$ produces $96.9 \%$ accuracy in mapping of water boundaries. The optical bands are not fit for the method, but while using TM band 5, the performance of density slicing in detecting water pixels is comparable with multispectral maximum likelihood algorithm (Frazier et al., 2000). Band 6 of OLI image provides similar data in the SWIR1 band $(1.57-16.5 \mu \mathrm{m})$, though the spectral range is a bit narrower than the TM band 5. Therefore, band 5 of Landsat- 5 images and band 6 of Landsat- 8 images were selected since they exhibit comparable spectral character suitable for the purpose of detecting water pixels. The greyscale image (band 5 for TM or band 6 for OLI) is segmented into water and non-water classes by thresholding method where the spatially continuous pixels are partitioned into two disjoint sets in reference to a fixed constant pixel value, called threshold value. The pixels with values less than the threshold yalue indicate water and such pixels were re-coded to 0 , while pixels with values greater than the threshold value signify nonwater and they were re-coded to 1 . Thus, thresholding converts the grey-level band images into a binary image by turning all water pixels to black and others to white. A DFPS search approach was used for fixing the threshold value.

\section{<Fig. 4>}

\subsubsection{Double-window flexible pace search}

The DFPS is a systematic approach to determine the optimum threshold value between change and no-change pixels while examining LULC transitions (Chen et al., 2003; He et al., 2010; Bhatti \& Tripathi, 2014). This technique is an improved version of Change Vector Analysis (CVA) which determines the threshold of change first and then determines change direction (from one category to another) by application of minimum-distance classification algorithm on direction cosines of the change vectors (Chen et al., 2003). DFPS 
approach has been widely used to determine optimum threshold value for recognizing vegetation, water and bare land in a thematic image while extracting built-up areas (He et al., 2010; Bhatti \& Tripathi, 2014). The technique is based on choosing an optimum threshold from representative training samples, which should contain all possible feature classes to represent in the study area optimally (Chen et al., 2003). It relies on determination of threshold value at the highest level of accuracy such that the value eliminates all the pixels under a targeted class from all other classes present in the sample area (Chen et al., 2003; He et al., 2010; Bhatti \& Tripathi, 2014). The technique involves some steps to apply in SLEA method (Fig 5).

\section{Fig. 5}

\subsubsection{Selection of typical sample area}

Selection of representative training sample areas in processed image is decisive for actual extraction of water areas. In this study, the sample water bodies have been selected through rapid visual survey of study area and visual interpretation of the processed image, subject to the condition that sample areas include only water pixels in inner window and surrounded by non-water pixels in the outer window (Fig 6).

$<$ Fig. 6>

\subsubsection{Determination of search range and pace}

In this stage, the threshold range has been setup using simple arithmetic difference between minimum pixel value (a) and the maximum pixel value (b) of the magnitude of change in processed image by first search (Chen et al., 2003; He et al., 2010; Bhatti \& Tripathi, 2014). The pace of first search, $P_{l}$ could be computed by Equation 1 (Chen et al., 2003).

$$
P_{1}=\frac{(b-a)}{m}
$$


where, $m$ is the positive integer that reveals the number of optimum threshold in a iteration search and it can be manually determined. The optimum thresholds to detect magnitude change pixels from training sample in a iteration search process are given within the range of $(a, b)$ as $\left(b-P_{1}, b-2 P_{1}, \ldots, b-m P_{1}\right)$. It is to be remembered that the value of $m$ has no bearing on the search process and ultimate results, but it is a time dependant parameter. A large yalue of $m$ increases to the number of optimum threshold during first search, but it gradually decreases as the search process is iterated (Bhatti \& Tripathi, 2014).

\subsubsection{Calculation of test parameter}

The procedure for calculating test parameter has been slightly modified from that suggested by Chen et al. (2003). A success rate of target pixel detection is defined to evaluate the performance of each potential threshold during one search process for identifying change/no-change pixels. The success rate $\left(L_{k}\right)$ is calculated for a potential threshold of $k$ using Equation 2.

$L_{k}=\left(\frac{A_{k_{1}}}{A_{1}} \times \frac{A_{k_{2}}}{A_{2}}\right) \times 100$

where, $A_{1}$ is the total number of pixels under water within the inner window frame, $A_{k_{1}}$ is the number of pixels detected correctly as water inside the inner window, $A_{2}$ is the total number of pixels in the non-water rectangular strip lying between the boundaries of outer and inner window, and $A_{k_{2}}$ is the number of pixels correctly detected as non-water in $A_{2}$.For all $\mathrm{m}$ thresholds in one particular search process, the maximum and minimum values of $L_{k}$ were calculated and assigned to $L_{\max }$ and $L_{\min }$, respectively. These two values were examined whether or not they satisfied the exit condition given in the final step of the DFPS process. If the exit condition was not satisfied, a new search began with a new search range $\left(k_{\max }-P_{1}\right.$, 
$k_{\max }+P_{1}$ ) and a new search pace that was calculated using Equation (2), where $k_{\max }$ was the threshold value corresponding to $L_{\max }$ in that particular search iteration.

\subsubsection{Condition to exit the iteration}

The condition to exit from the iteration search process was performed until differences between $\mathrm{L}_{\max }$ and $\mathrm{L}_{\min }$ satisfied the stipulation given in Equation 3 .

$$
L_{\max }-L_{\min } \leq \delta
$$

where $\delta$ denotes an acceptable error in the search process, and its value is 1 in case of an inter-type image. The desired threshold value to separate water areas from other areas in the continuous image was equivalent to $L_{\max }$ in the final iteration of DEPS search technique. Thus, the said value has been employed in continuous layers of band 5 (for TM images of 2000, 2005 and 2010) and band 6 (for OLI image of 2015) to separate water bodies; waterpixels were assigned a value of 0 and the rest were given a value of 1 .

The output binary image was multiplied to their corresponding multi-band image so that the water pixels in each layer of the stacked images receive zero value while the other pixels retain their original values. Consequently, the water areas were eliminated and the output images were ready for subsequent analyses.

\subsubsection{Step 2: Elimination of vegetation class}

The elimination of vegetation pixels follows the same technique as employed for the delineation of water (see Step 1 above); the only difference is that it was applied to the NDVI images instead of any single band. Continuous NDVI images were obtained through raster calculation using Equation 4 that involves Red (R) and Near Infrared (NIR) bands.

$$
N D V I=\frac{N I R-R}{N I R+R}
$$


The red band corresponds to the band 3 of TM and band 4 of OLI, while the infrared band corresponds to the band 4 of TM and band 5 of OLI images. Accordingly, the formula was applied for preparing the NDVI image.

The DFPS method, with all its steps, was applied to the NDVI images to detect the pixels that cover the green areas including woodlands, crop fields and vegetated wetlands. The threshold based classification segmented the vegetation pixels from the pixels under other land classes and this classified image was re-coded to obtain a binary image with yalues 0 for vegetation and 1 for others. The image was then multiplied to the output image from step 1 to eliminate the vegetation pixels. The multi-band images layers now comprises the pixels under only two categories- built-up and bare land.

\subsubsection{Step 3: Separating bare lands from built-up areas}

In an effort to segregate built-up pixels from the bare land pixels, one Logit model each was formulated for the images of 2000, 2005, 2010 and 2015 on the basis of the DN values of the pixels sampled from the corresponding images obtained from Step 2 above.The proposed method includes several components: (1) training and test data preparation;(2) formulation of Logit model; (3) accuracy assessment of the model using test data set; and (4) selection of the final model by repeating the steps from 2 to 3 until the best level of accuracy is achieved.

\subsubsection{Sampling pixels and preparation of data sets}

In order to sample pixels, we carried out unsupervised classification of the input image into two categories for a primary detection of built-up and bare land pixels, and both the categories were sampled randomly. The sampled points, originally saved in shape file format, were converted into a Google Earth (GE) Keyhole Markup Language (KML) file for verification of the land class that the sample points represent. In the process, we took the advantage of the availability of historical high resolution Landsat GeoCover imageries for the 
study area on GE. Moreover, horizontal positional accuracy of GE high-resolution imagery is sufficient for assessing moderate-resolution satellite images for majority of the world cities (Potere, 2008). Sample points in KML file were drawn on GE images and any mismatch in land class category of the sample points, led to withdrawal of the points from the sample pool. A final round of verification was done with ground-based survey using Global Positioning System (GPS) receivers and parcel level detail landuse map of municipal wards available for the study period. The size of the sample was 576, same for all the images processed. Sampling was followed by building of database that includes the DN values of the sampled pixels in each band of the respective layer-stacks (independent variables), and the land class of the pixels in a binary format, 1 for built-up and 0 for bare land (dependent variable). The data was split into two parts in the proportion of 60 to 40 for preparing the training and test data sets, respectively, which were used in formulating the Logit model.

\subsubsection{Logit model}

Logit model, also known as logistic regression (Dyke and Patterson, 1952; Cox, 1958; Cox, 1970; Sankoff and Labov, 1979), is a promising approach for modeling binary responses $Y=y_{i} \in\{1,0\}$ as the linear combination of one or more continuous or categorical predictor variables $\left(x_{1}, x_{2}, x_{3} \ldots \ldots x_{n}\right)$, plus some normalized random error, $\varepsilon$ (and optionally the intercept $\beta_{0}$, expressed as (Equation 5,6 and 7):

$$
\begin{aligned}
& Y=\beta_{0}+\beta_{1} x_{1}+\beta_{2} x_{2}+\ldots \ldots \ldots .+\beta_{n} x_{n}+\varepsilon \\
& E(Y)=\beta_{0}+\beta_{1} x_{1}+\beta_{2} x_{2}+\ldots \ldots \ldots+\beta_{n} x_{n} \\
& E(Y)=\mathbf{x}^{\prime} \boldsymbol{\beta}
\end{aligned}
$$

where, $E(Y)$ is the expected value of $Y$, vector $\mathbf{x}^{\prime}=\left(1, \mathbf{x}_{1}, x_{2}, \ldots \ldots ., x_{n}\right)^{T}$ and vector $\boldsymbol{\beta}=\left(\beta_{0}, \beta_{1}, \beta_{2}, \ldots \ldots \ldots, \beta_{n}\right)^{T}$.In order to accommodate categorical nature of $Y$, the model considers $p=P\left(Y=1 \mid \mathbf{x}^{\prime}\right)$ i.e. probability of the success of an observation that assumes a 
logistic distribution bounded between 0 and $1\left(p=e^{\mathbf{x}^{\prime} \mathbf{\beta}} / 1+e^{\mathbf{x}^{\prime} \mathbf{\beta}}=1 / 1+e^{-\mathbf{x}^{\prime} \boldsymbol{\beta}}\right)$ and uses natural logarithm of odds called Logit $[\operatorname{logit}(p)=\ln (p / 1-p)]$ as the output variable that ranges unboundedly from $-\infty$ to $+\infty$. Thus, the Logit function transforms the probability space into a log-odds space where the logistic relation becomes linear as (Equation 8).

$$
\ln \frac{p}{1-p}=Y^{\prime}=\mathbf{x}^{\prime} \boldsymbol{\beta}
$$

The ordinary Logit model aims at estimating the parameters $\left(\beta_{0}, \beta_{1}, \beta_{2}, \ldots, \beta_{n}\right)$ from a training data with observed responses $y_{1}$ through $y_{m}$, by way of maximizing a likelihood function defined as (Equation 9):

$$
L\left(p ; y_{1}, y_{2}, \ldots, y_{m}\right)=f\left(y_{1}, y_{2}, \ldots, y_{m} ; p\right)=\prod_{i=1}^{m} P\left(Y=y_{i}\right)=p^{k}(1-p)^{m-k}
$$

where, $k=\sum_{i=1}^{m} y_{i}$ and $0 \leq p \leq 1$.

Statistical conditions required for application of Logit model are fulfilled in the present context of multiband image transformation to obtain a binary image depicting probability of a pixel to be under built-up class. Logistic regression is independent of many of the vital assumptions made in the ordinary least square approach. It does not need that the dependent and independent variables to be in a linear relationship, because log-odds transformation of the dependent variable makes the system capable of handling all types of relationship in a linear framework. It is not mandatory for the independent variables to be multivariate normal and homoscedastic. Land class of a sample pixel was entered into the model in a binary form because the logistic regression needs its dependent variable to be dichotomous. The issue of over fitting or under fitting of the model was tackled by retaining only the significant independent variables in the model. The sampling strategy complies with the recommendation of 20-30 samples per independent variable. 
For the present purpose of separating built-up areas from bare lands, Logit model is implemented on the multiband image containing those two land classes only (output from Step 2). This entails digital transformation of input image into a single band output image by combining selected bands through linear operation.

\subsubsection{Assessment of model fit}

An iterative modeling strategy was adopted where predictive bands were progressively removed (Campling et al., 2002), based on significance test for the co-efficients in the model using Wald's method. The Wald's test considers square of the ratio of regression coefficients to its standard error and thus assesses the statistical significance of each coefficient in the model. The test suggested the variables to be retained in the next round of repetition. On every reiteration, fitting of the model was further confirmed by assessing its predictive capacity through application of the model on the test data, at a chosen level of probability. A model is finalized when it includes only the statistically significant predictive bands and has attained a satisfactory level of accuracy $(>95 \%)$ in predicting the output.

Implementation of the final model on the appropriate image produces a single band raster layer in greyscale where the pixel value represents the probability of a pixel to be the built-up area. Finally, segmentation of the output image by use of DFPS technique gives the desired map of built-up area.

\section{Results and discussion}

The mapping of mixed and swift urban growth and their spatial pattern in relation to LULC is an indispensablerequirementfor urban planning. One of the foremost tasks for this purpose is the actual mapping of urban built up area. The issue is more crucial for the cities of the developing countries like India where haphazard unplanned use of land has led to mixed type of development where the continuity of a land class is often interrupted by 
appearance of another class. This situation makes the extraction of built-up area challenging due to adjacency and similar spectral response of built-up area and bare land. The problem is still unresolved in spite of several attempts made to address the issue.

\subsection{Previous approaches: NDBI and BAEM}

The NDBI Zha et al. (2003) has been useful for automatic mapping urban built-up areas using TM data. It was prepared on the basis of the unique spectral signatures and responses of built up land and other LULC. The authors have argued that the built up areas and open bare land provide a sharp increment in their reflectance from band 4 to band 5 and this pace of increment greatly exceeds that of any other LULC (Zha et al., 2003). The normalized differentiation of thesetwo bands is given by Zha et al., 2003 as (Equation 10):

$$
N D B I=\frac{(T M 5-T M 4)}{(T M 5+T M 4)}\left(\begin{array}{l}
\text { close to } 0=\text { vegetation } \\
0 \text { to }-1=\text { waterbodies } \\
0 \text { to } 1=\text { built up }
\end{array}\right)
$$

The index was developed through simple arithmetic manipulation of two bands from TM satellite imagery. In the output image, the values range between -1 and 1 where the built up areas and bare land pixels have positive values which allow the built up areas to be mapped automatically.

Recently, the applicability of NDBI to the Landsat-8 OLI imagery was examined and tested by Bhatti \& Tripathi (2014), and they proposed a new technique for urban built up area extraction by utilizing PCA of similar spectral bands and thermal bands of OLI data. The new method called BAEM was the revised version of a modified NDBI approach (He et al., 2010), and was employed on Landsat-8 OLI imagery. The possibility of built up areas is given by Bhatti \& Tripathi (2014) as:

$$
B A E M=(N D B I-N D V I-M N D W I)\left(\begin{array}{l}
\text { high } D N=\text { built up } \\
\text { low } D N=\text { other land }
\end{array}\right)
$$


The BAEM approach is an amalgamation and integration of Land Surface Temperature (LST), NDVI, and Modified Normalized Difference Water Index (MNDWI) given by $\mathrm{Xu}$ (2005). The BAEM approach was able to extract the built up areas from OLI images more satisfactorily as compared to the modified NDBI approach. Instead of using binary NDBI, NDVI and MNDWI images directly, continuous images of these indices were employed and the outputs were re-coded to map the built-up areas based on optimal threshold value determined through the DFPS method.

The aforementioned methods of NDBI and BAEM were applied and tested in this study, and it was found that both the methods could not completely separate built-up areas from bare land in case of Kolkata, one of the leading metropolitan areas in eastern India. These two techniques of built-up area extraction are more suitable for temperate climate where a distinct contrast exits in spectral reflectance from built up lands and open bare lands. In the case of tropical environment, however, these methods overestimates the built-up areas because no distinct contrast exits in spectral reflectance from built up lands and open bare lands; both the land categories are classified as built up in some parts of the study area, particularly in margins of the city.Results show that many of the built-up areas could not be identified by the index-based methods due to less difference between spectral reflectance between built-up areas and other land-classes in the bands used in building the indices. NDBI and BAEM techniques returned exceptionally good results for continuously built-up areas but failed to detect built-up pixels from areas of mixed-type LULC. Thus, for the tropical cities with haphazard growth, these methods do not provide the assessment of urban built up areas with desirable accuracy because no spatial thresholding method has been suggested to separate the misclassified pixels. This is a major problem and challenge for urban planning and policy implementation purposes.

\subsection{Proposed SLEA approach}


The approaches developed so far for built-up area extraction suffers from generic limitations either from technical or from methodological or from applicative point of view. The present study is an attempt to eliminate those discrepancies and proposes a simple technique that involves application of Logit model and DFPS approach to precisely map urban built-up areas by successive elimination of other land classes. The suggested method is more straightforward and eliminates users' control over the output. When applied in case of Kolkata metropolis, it turned out to be more efficient than the other methods available.

The impervious surfaces have effects on the land surface temperature which is directly related to their thermal properties and therefore, the impervious urban surface covers exhibit direct relation with the intensity of reflectance in the thermal bands (Oke, 1973; Weng, 2001; Yuan \& Bauer, 2007). The uncovered land parcels within the built-up areas have spectral reflectance in thermal bands which is comparable to that of the impervious built-up areas. Techniques of built-up area extraction using thermal bands are, therefore, prone to overstimulation. For this, thermal bands were excluded from the analysis. The method, therefore, only considers the optical bands of TM and OLI sensors. After elimination of the water bodies and the green covers, Logit model was employed to eliminate bare lands. The Logit model was finalized on the basis of best level of accuracy obtained through several trials with different combinations of the bands. The model retains only those bands for which the co-efficient in the linear combination are statistically significant. Thus the built-up areas extraction approach was simple and follows a strategy of eliminating other land classes to finally obtain the built-up areas.

The spectral features and ranges of TM bands differ from those of OLI, accordingly, it was essential to examine the signatures of spectral ranges of LULC class in different bands of TM and OLI data before applyingthis sample based approach of eliminating the unintended land classes and subsequent extraction of built-up areas. For this reason, the spectral response 
of water bodies, vegetation areas and built-up areas in different band of TM and OLI were examined after necessary pre-processing. It was found that the band $4(0.76-0.90 \mu \mathrm{m})$ and band $5(1.55-1.75 \mu \mathrm{m})$ of TM data are closely analogous to band $5(0.85-0.88 \mu \mathrm{m})$ and band 6 $(1.57-1.65 \mu \mathrm{m})$ of OLI data, respectively, in respect of spectral character. The spectral responses of the major land classes differ significantly in some bands. For example, water responds quite differently than built-up and vegetation class in band 5 and 6 of OLI while such variation is distinct in band 4 and 5 of TM (Fig. 7). Importantly, Band 4 and band 5 of TM are very strongly correlated at a high level of statistical significance and a similarly strong correlation exists between the band 6 and 7 of OLI (Bhatti \& Tripathi, 2014).

$<$ Fig. 7 $>$

In SLEA, each of the land classes to be eliminated are identified and separated out of the original raster image sequentially. The continuous image was first converted to unsigned integer, and then its histogram was plotted and examined to set the initial range of search. The search process for identifying water pixels in the Landsat 8 OLI image of 2015 and the results obtained thereby are shown in the Table 2, as an example. This is a 16 bit data with $\mathrm{DN}$ values ranging between 0 and 65535 . For the first cycle, 13 individual searches were desired and accordingly threshold values were set at an interval of 5000 within the said range of DN values. The first search turned out to be successful (with success rate $>0$ ) for the threshold values 15535,10535 and 20535 suggesting that the second round of searches to start with threshold value 15535 and be continued till 5535. The pace or interval for the second search was considered to be 1000. In subsequent searches, both the search range and pace gradually diminished to achieve a precise threshold value for which the success rate attains the maxima. For the image under consideration, the search process identified 8355to be the optimal DN value for segmentation of the image into water and non-water classes with 
a success rate of $96.35 \%$. The Table 3 summarises the results of DFPS run for all other similar pursuits of image segmentation involved in the study.

$<$ Table 2> An example of the DFPS for the determination of optimal threshold value of water pixels of the Landsat-8 OLI image of 2015

$<$ Table 3>Summary results of the DFPS for determination optimum threshold values in eliminating the water and vegetation pixels and final extraction of built-up areas.

After eliminating the water and vegetation pixels (values recoded as zero), the multiband images with layers of selected bands were sampled for preparing pixel-based database to be employed in formulating Logit model that uses the image bands as the independent variables. The best fit Logit model transforms the corresponding multi-band image into a binary image which when segmented through DFPS delineates the built-up areas (Fig. 8). In formulating the Logit model, an iterative approach was adopted that initiated with all the bands in the image progressively discarded insignificant bands from the model. Optimality of the model was judged by the level of accuracy measured with reference to the test data. Results show that for the TM image of 2000, the best model involves band 5 and band 7 with an accuracy of $98.21 \%$, signifying that the model is highly accurate in distinguishing built-up area from bare lands (Table 4). The results for the images of other years are summarized in Table 3. The pixels with values abovethe optimum threshold were classified as built-up areas (Fig. 9).

$<$ Table $4>$ Co-efficient values of Logit model for built up area extraction. $<$ Fig. 8 $>$

$<$ Fig. 9 $>$

\subsection{Built-up areas and level and agreement of accuracy}


In order to assess the classification performance, the results of the proposed SLEA were verified at 350 locations by rapid visual survey with corresponding image pixels using a stratified random sampling technique (Congalton, 1991). At first, a specific area was split into two strata, built-up areas and non-built-up areas, and then samples were taken from each one stratum on the basis of proportion in the output image (Bhatti \& Tripathi, 2014). In addition, both NDBI and BAEM approaches were also used to generate a map of built-up areas, which was tested using the same accuracy assessment method in order to compare the performance of the three approaches (Fig. 10). Producer and user accuracy of three approaches were compared to each other for assessing the classification efficiency. Selected sampled areas were visually observed to comprehend the discrepancies in the outputs of three approaches. The Fig. 10 demonstrates the misclassification of built-up area in NDBI and BAEM approach very clearly. The red 'A' rectangles indicate sample areas with large number of bare land parcels situated within the developed areas which could not be detected by NDBI and BAEM methods and those bare lands have been classed under the built-up areas. The disconnected built-up areas interspersed with homestead have been underestimated in both NDBI and BAEM approaches. Such areas were sampled, indicated by red 'B' rectangles in the Fig. 10.

$<$ Fig. 10 $>$

The confusion matrix has been derived for NDBI, BAEM and SLEA to assess the accuracy of the three approaches (Table 5). Results of the proposed SLEA were $95.33 \%$ accurate on the whole, while those derived by the NDBI and BAEM approaches returned an overall accuracy of $83.67 \%$ and $89.33 \%$, respectively. These comparative accuracy discrepancies occur mainly due to incorrect detection of built-up and non-built-up areas in different approaches. The commission error greater than the omission error in NDBI and BAEM approaches has resulted in outputs containing some pixels wrongly detected as built-up areas. However, the 
least omission error signifies that the approach is capable to capture the built-up areas well (Table 6). Nevertheless, least values of omission and commission errors, represented by the kappa index, suggested that the SLEA has the highest agreement level or overall accuracy than the NDBI and BAEM approaches.

$<$ Table 5 $>$ Confusion matrix for NDBI, BAEM and SLEA

$<$ Table 6> Summary of the accuracy assessment of the images derived by NDBI, BAEM and SLEA

For the purpose of comparison, the input TM and OLI images and final outputs of three built-up areas extraction approaches have been displayed in Fig. 10 showing the same sample locations. It was found that the NDBI and BAEM approaches have over classified (inclusion of bare lands) the built-up areas as compared to the SLEA. The NDBI and BAEM classifications include higher commission error in the outputs than that obtained through the SLEA method. The use of thermal bands in BAEM approach helped in separating less dense built-up areas from other LULC types (Bhatti \& Tripathi, 2014). However, in case of Kolkata, inclusion of thermal bands and seasonality in BAEM approach misclassified a considerable number of bare lands pixels as built-up areas, and thus reduced the overall accuracy of BAEM approach. On the other hand, NDBI approach is also incapable to segregate built-up areas from open bare lands because built-up areas and bare lands have comparable spectral signatures in TM bands (Zha et al., 2003). Zha et al., (2003) have suggested that the drawback may be tackled through the integration of spatial knowledge, that the bare lands are located next to water. But obviously, this is totally a time dependant protocol. The established methods in use could not completely separate the bare lands from built-up areas because of the resemblances in spectral response of these two LULC classes which may be due to monotonous nature of surface, seasonality and climate type of the study area (Zha et al., 2003; Herold et al. 2004; Lu \&Weng, 2004; Lwin \& Murayama, 2013; Bhatti 
\& Tripathi, 2014).Thus, in case of Kolkata metropolis, the rationale for the high commission error may be endorsed to spectral mixing of built-up pixels with bare lands. It is interesting to note that SLEA was able to recognize water, vegetation and bare lands from continuously built-up areas, and to eliminate them for separating out the built-up areas. Moreover, the integration of optical band-based Logit model for segregating built up areas from bare lands increased the performance of the proposed land class elimination technique.

\section{Conclusion}

Both NDBI and BAEM approaches were capable to map continuously built-up areas but they could not perform satisfactorily when applied to highly intermixed type built-up areas of tropical environment as in the case of Kolkata metropolis. This study proves that the accuracy and objectivity of NDBI and BAEM approaches decrease towards urban fringe areas where the built-up areas are dotted with bare lands. Both the methods wrongly detected most of the open bare lands as built-up areas. NDBI and BAEM approaches are based on indices which rely on some fixed bands and if any two types of objects have similar spectral responses in these bands, and then the indices fail to distinguish between the objects in question. In the present context, the built-up areas and the bare lands respond comparably to energy in thermal and some visible bands, particularly during the summer. These shortcomings were addressed in this study to develop a method that was simultaneously applicable to both TM and OLI sensor data in order to assess urban growth. The new approach, SLEA, extracts and maps the built-up areas by eliminating water bodies, vegetation and bare lands. This method is capable of distinguishing built-up areas from bare land parcels by using Logit model which flexibly involves only those bands of an image to which the land classes respond distinctly. The Logit model is developed on the basis of sample pixels collected from the image in use, which makes the method free from any theoretical assumption regarding spectral response of 
the objects. The SLEA enables to map built-up areas (excluding barren lands) objectively with higher consistency and accuracy even when applied to images of tropical urban areas like KMA. In comparison to NDBI and BAEM approaches, SLEA maps the built-up areas at higher degree of spatial and visual accuracy because SLEA can easily exclude the bare lands from the built-up areas. The confusion matrix has been derived for NDBI, BAEM and SLEA to assess the accuracy of the three approaches. Results of the proposed SLEA were $95.33 \%$ accurate on the whole, while those derived by the NDBI and BAEM approaches returned an overall accuracy of $83.67 \%$ and $89.33 \%$, respectively. SLEA does not entail a multifaceted mathematical computation protocols or any spatial filtering technique with user defined window at the cost of spatial accuracy of the output. Its methodological simplicity substantially expedites the built-up area extraction accomplished by simple arithmetic manipulation and recoding of intermediate images.

\section{Acknowledgements}

We are grateful to the Earth Resources Observation and Science Centre (EROS) and United States Geological Survey (USGS) for offering Landsat data free of charge. We also thank the editor and three anonymous reviewers for their constructive comments, which helped us to improve the manuscript. 


\section{References}

Adam, H. E., Csaplovics, E., \& Elhaja, M. E. 2016.”A Comparison of Pixel-Based and Object-Based Approaches for Land Use Land Cover Classification in Semi-Arid Areas, Sudan". In IOP Conference Series: Earth and Environmental Science (Vol. 37, No. 1, p. 012061). IOP Publishing.

Aplin, P. 2006. "On Scales and Dynamics in Observing the Environment." International Journal of Remote Sensing, 27(11), 2123-2140.

Askne, J., Santoro, M., Smith, G., \&Fransson, J. E. 2003."Multitemporal Repeat-Pass SAR Interferometry of Boreal Forests."Geoscience and Remote Sensing, IEEE Transactions on, 41(7), 1540-1550.

Bhatta, B. 2009. "Analysis of Urban Growth Pattern Using Remote Sensing and GIS: A Case Study of Kolkata, India.” International Journal of Remote Sensing, 30(18), 4733-4746.

Bhatti S. S., and Tripathi N. K. 2014. "Built-up Area Extraction Using Landsat 8 OLI Imagery." GIScience \& Remote Sensing 51 (4): 445-467. doi:10.1080/15481603.2014.939539.

Bouzekri, S., Lasbet, A. A., \& Lachehab, A. (2015). A new spectral index for extraction of built-up area using landsat-8 data. Journal of the Indian Society of Remote Sensing, 43(4), 867-873.

Campling, P., Gobin, A., \&Feyen, J. 2002. "Logistic Modeling to Spatially Predict the Probability of Soil Drainage Classes.” Soil Science Society of America Journal, 66(4), 1390-1401.

Chen, J., P. Gong, C. He, R. Pu, and P. Shi. 2003. "Land-Use/Land-Cover Change Detection Using Improved Change-Vector Analysis." Photogrammetric Engineering \& Remote Sensing 69 (4): 369-379.

doi:10.14358/PERS.69.4.369.

Cleve, C., M. Kelly, F. R. Kearns, and M. Moritz. 2008. "Classification of the Wildland-Urban Interface: A Comparison of Pixel- and Object-Based Classifications Using High-Resolution Aerial Photography." Computers, Environment and Urban Systems 32 (4): 317-326. doi:10.1016/j.compenvurbsys.2007.10.001.

Congalton, R. G. 1991. "A Review of Assessing the Accuracy of Classifications of Remotely Sensed Data." Remote Sensing of Environment 37 (1): 35-46. doi:10.1016/0034-4257(91) 90048-B.

DeFries, R. 2008. "Terrestrial Vegetation in the Coupled Human-Earth System: Contributions of Remote Sensing." Annual Review of Environment and Resources, 33, 369-390.

DeFries, R., and Pandey, D. 2010. "Urbanization, the Energy Ladder and Forest Transitions in India's Emerging Economy." Land Use Policy, 27(2), 130-138.

Deng, C., and C. Wu. 2013. “A Spatially Adaptive Spectral Mixture Analysis for Mapping Subpixel Urban Impervious Surface Distribution." Remote Sensing of Environment 133: 62-70. doi:10.1016/j.rse.2013.02.005.

Estoque, R. C., \& Murayama, Y. (2015). Classification and change detection of built-up lands from Landsat-7 $\mathrm{ETM}+$ and Landsat-8 OLI/TIRS imageries: A comparative assessment of various spectral indices. Ecological Indicators, 56, 205-217.

Frazier, P. S., \& Page, K. J. 2000).“Water Body Detection and Delineation with Landsat TM Data." Photogrammetric Engineering and Remote Sensing, 66(12), 1461-1468.

Gangkofner, U. G., P. S. Pradhan, and D. W. Holcomb. 2008. "Optimizing the High-Pass Filter Addition Technique for Image Fusion.” Photogrammetric Engineering \& Remote Sensing 74 (9): 1107-1118. doi:10.14358/PERS.74.9.1107.

Gibril, M. B. A., Bakar, S. A., Yao, K., Idrees, M. O., \& Pradhan, B. (2017). Fusion of RADARSAT-2 and multispectral optical remote sensing data for LULC extraction in a tropical agricultural area. Geocarto International, 32(7), 735-748.

Gibson, P. J., Power, C. H., Goldin, S. E., \& Rudahl, K. T. 2000.“Introductory Remote Sensing: Digital Image Processing and Applications" (Vol. 11). London, UK: Routledge. 
Griffiths, P., P. Hostert, O. Gruebner, and V. D. L. Sebastian. 2010. "Mapping Megacity Growth with MultiSensor Data.” Remote Sensing of Environment 114 (2): 426-439. doi:10.1016/j.rse.2009.09.012.

Guindon, B., Y. Zhang, and C. Dillabaugh. 2004. "Landsat Urban Mapping Based on a Combined SpectralSpatial Methodology.” Remote Sensing of Environment 92 (2): 218-232. doi:10.1016/ j.rse.2004.06.015.

He, C., P. Shi, D. Xie, and Y. Zhao. 2010. "Improving the Normalized Difference Built-Up Index to Map Urban Built-Up Areas Using a Semiautomatic Segmentation Approach.” Remote Sensing Letters 1 (4): $213-221$. doi:10.1080/01431161.2010.481681.

Herold, M., D. A. Roberts, M. E. Gardner, and P. E. Dennison. 2004. "Spectrometry for Urban Area Remote Sensing-Development and Analysis of a Spectral Library from 350 to 2400 Nm." Remote Sensing of Environment 91 (3-4): 304-319. doi:10.1016/j.rse.2004.02.013.

Jones, P. D., Lister, D. H., \& Li, Q. 2008. "Urbanization Effects in Large-Scale Temperature Records, with an Emphasis on China." Journal of Geophysical Research: Atmospheres, 113(D16).

Ke, Y., Im, J., Lee, J., Gong, H., \&Ryu, Y. 2015. "Characteristics of Landsat 8 OLI-Derived NDVI by Comparison with Multiple Satellite Sensors and In-Situ Observations." Remote Sensing of Environment, 164, 298-313.

Khan, A., \&Chatterjee, S. 2016. "Numerical Simulation of Urban Heat Island Intensity Under Urban-Suburban Surface And Reference Site In Kolkata, India.” Modeling Earth Systems and Environment, 2(2), 1-11.

Khan, A., Chatterjee, S., \&Bisai, D. 2015.“On the long-term variability of temperature trends and changes in surface air temperature in Kolkata Weather Observatory, West Bengal, India." Meteorology Hydrology and Water Management. Research and Operational Applications, 3(2), 9-16.

Liu, T., \& Yang, X. (2015). Monitoring land changes in an urban area using satellite imagery, GIS and landscape metrics. Applied Geography, 56, 42-54.

Lo, C. P., \& Choi, J. 2004. “A Hybrid Approach to Urban Land Use/Cover Mapping Using Landsat 7 Enhanced Thematic Mapper Plus (ETM+) Images.” International Journal of Remote Sensing, 25(14), 2687-2700.

Lu, D., and Q. Weng. 2004. "Spectral Mixture Analysis of the Urban Landscape in Indianapolis with Landsat ETM+ Imagery.” Photogrammetric Engineering \& Remote Sensing 70 (9): 1053-1062. doi:10.14358/PERS.70.9.1053.

Lu, N., Hernandez, A. J., \& Ramsey, R. D. (2015). Land cover dynamics monitoring with Landsat data in Kunming, China: a cost-effective sampling and modelling scheme using Google Earth imagery and random forests. Geocarto International, 30(2), 186-201.

Lwin, K. K., and Y. Murayama. 2013. "Evaluation of Land Cover Classification Based on Multispectral versus Pansharpened Landsat ETM+ Imagery." GIScience \& Remote Sensing 50 (4): 458-472.

Mushore, T. D., Mutanga, O., Odindi, J., \& Dube, T. (2017). Assessing the potential of integrated Landsat 8 thermal bands, with the traditional reflective bands and derived vegetation indices in classifying urban landscapes. Geocarto International, 32(8), 886-899.

Mushore, T. D., Mutanga, O., Odindi, J., \& Dube, T. (2017). Assessing the potential of integrated Landsat 8 thermal bands, with the traditional reflective bands and derived vegetation indices in classifying urban landscapes. Geocarto International, 32(8), 886-899.

Nandy, D. R. 2007. "Need for Seismic Microzonation of Kolkata Megacity.” In Proceedings of workshop on microzonation, Indian Institute of Science, Bangalore, India (Vol. 2627).

Nath, S. K., M. D. Adhikari, N. Devaraj, and S. K. Maiti. 2015. "Seismic Vulnerability and Risk Assessment of Kolkata City, India." Natural Hazards and Earth System Sciences 15 (6) :1103-1121.

Oke, T. R. 1973. “City Size and the Urban Heat Island.” Atmospheric Environment (1967) 7 (8): 769-779. doi:10.1016/0004-6981(73)90140-6. 
Pant, M., Deep, K., Bansal, J. C., Nagar, A., \& Das, K. N. (Eds.). 2016. "Proceedings of Fifth International Conference on Soft Computing for Problem Solving:” SocProS 2015 (Vol. 1). Springer.

Parker, D. E. 2010. “Urban heat island effects on estimates of observed climate change.” Wiley Interdisciplinary Reviews: Climate Change, 1(1), 123-133.

Piyoosh, A. K., \& Ghosh, S. K. (2017). Development of a modified bare soil and urban index for Landsat 8 satellite data. Geocarto International, 1-20.

Potere, D. 2008. "Horizontal Positional Accuracy of Google Earth’s High-Resolution Imagery Archive.” Sensors, 8(12), 7973-7981.

Powell, R. L., D. A. Roberts, P. E. Dennison, and L. L. Hess. 2007. "Sub-Pixel Mapping of Urban Land Cover Using Multiple Endmember Spectral Mixture Analysis: Manaus, Brazil.” Remote Sensing of Environment 106 (2): 253-267. doi:10.1016/j.rse.2006.09.005.

Qian, J., Zhou, Q., \&Hou, Q. 2007. “\{Comparison of Pixel-Based And Object-Oriented Classification Methods For Extracting Built-up Areas in Aridzone.” In ISPRS Workshop on Updating Geo-spatial Databases with Imagery \& The 5th ISPRS Workshop on DMGISs (pp. 163-171).

Registrar General I 2011. “Census of India 2011: Provisional Population Totals-India Data Sheet. Office of the Registrar General Census Commissioner, India.’Indian Census Bureau.

Sameen, M. I., \& Pradhan, B. (2016, June). A novel built-up spectral index developed by using multi-objective particle-swarm-optimization technique. In IOP Conference Series: Earth and Environmental Science (Vol. 37, No. 1, p. 012006). IOP Publishing.

Stone, B. 2007. "Urban and Rural Temperature Trends in Proximity to Large US Cities: 1951-2000." International Journal of Climatology, 27(13), 1801-1807.

USGS. 2013. "Using the USGS Landsat 8 Product.” Accessed November 7. https://landsat.usgs. gov/Landsat8_Using_Product.php.

Wang, Z., Gang, C., Li, X., Chen, Y., \& Li, J. (2015). Application of a normalized difference impervious index (NDII) to extract urban impervious surface features based on Landsat TM images. International Journal of Remote Sensing, 36(4), 1055-1069.

Weng, Q. 2001. “A Remote Sensing-GIS Evaluation of Urban Expansion and Its Impact on Surface Temperature in the Zhujiang Delta, China." International Journal of Remote Sensing 22 (10): 1999-2014.

Xu, H. 2008. “A New Index for Delineating Built-Up Land Features in Satellite Imagery.” International Journal of Remote Sensing 29 (14): 4269-4276. doi:10.1080/01431160802039957.

Yuan, F., and M. E. Bauer. 2007. "Comparison of Impervious Surface Area and Normalized Difference Vegetation Index as Indicators of Surface Urban Heat Island Effects in Landsat Imagery." Remote Sensing of Environment 106 (3): 375-386. doi:10.1016/j.rse.2006.09.003.

Zha, Y., J. Gao, and S. Ni. 2003. "Use of Normalized Difference Built-Up Index in Automatically Mapping Urban Areas from TM Imagery." International Journal of Remote Sensing 24 (3): 583-594. doi:10.1080/01431160304987.

Zhai, K., Wu, X., Qin, Y., \& Du, P. (2015). Comparison of surface water extraction performances of different classic water indices using OLI and TM imageries in different situations. Geo-spatial Information Science, 18(1), 32-42.

Zhang, Q., G. Pavlic, W. Chen, R. Fraser, S. Leblanc, and J. Cihlar. 2005. “A Semi-Automatic Segmentation Procedure for Feature Extraction in Remotely Sensed Imagery." Computers \& Geosciences 31 (3): 289-296. doi:10.1016/j.cageo.2004.10.003. 
Fig. 1 The KMA in FCC of satellite image (2005).

Fig. 2 Spectral signatures of built-up area, bare land, water body and vegetation area in (a) optical bands 1-5 and 7 of Landsat-5 TM and (b) optical bands 2-7 of Landsat-8 OLI.

Fig. 3 Landsat-8 OLI in true colour composite (a) before resolution merging (30m spatial resolution) and (b) after resolution merging (15m spatial resolution). This illustrates the visual difference between non-enhanced and spatially enhanced image, at the location of Salt Lake City, Kolkata. The increase in sharpness and level of detail in the enhanced image obtained by merging original low resolution band images with high resolution image $(15 \mathrm{~m}$ spatial resolution) using a bilinear 4-nearest neighbour algorithm.

Fig. 4 Graphical flow chart for step wise elimination and extraction of water bodies, vegetation area, bare land and built up area from Landsat image.

Fig. 5 Diagrammatic representation of DFPS process for determination of threshold DN value that segments the NDVI image into vegetated and other areas. Gradual narrowing of search range and shortening of pace range increase success rate of the search. Iterative searching finally determines the threshold value to be 0.25 with the highest success rate of 96.26 for this example of thresholding NDVI image derived from Landsat-5 TM of 2000.

Fig. 6 (a-a') The OLI image (bands 3, 4, 5 as red-green-blue) of 2015, (b) output of vegetation area segmentation from NDVI image and ( $\left.b^{\prime}\right)$ output of water bodies segmentation from band 6. Red rectangles in each panel show the sample areas where the DFPS approach applied to determine threshold values.

Fig. 7 Scatter plots showing the correlation between (a) band 4 (x-axis) and band 5 (y-axis) (b) band 4 (x-axis) and band 5 (y-axis) and (c) band 5 (x-axis) and band 6 (y-axis) for 2005; 2010 and 2015 respectively for (a-b-TM data) and (c-OLI data). The Pearson's correlation value (R) of (a) 0.951, 0.942 and 0.961; (b) 0.962, 0.951 and 0.976 and (c) 0.957, 0.964 and 0.941 for water bodies, vegetation areas and built-up areas respectively.

Fig. 8 Fitting of Logit models for separating built-up areas from bare lands in the images (water bodies and vegetation areas eliminated): 2000, 2005, 2010 and 2015. Bold numerics denote image bands involved in the best fit model with highest accuracy.

Fig. 9 Map of built-up areas in KMA derived from satellite images through application of SLEA for (a) 2000 (b) 2005 (c) 2010 and (d) 2015.

Fig. 10 Comparison of the results from the NDBI, BAEM and SLEA at sample locations, (a$a^{\prime}$ ) Landsat-5 TM and Lansat-8 OLI of 2010 and 2015, respectively; (b-b') output from NDBI and BAEM respectively; (c-c') output from SLEA for TM and OLI, respectively. Red A rectangles in each panel show the places where the NDBI and BAEM approaches incorrectly extracted other land covers as built-up areas and red B rectangles show the places where the NDBI and BAEM approaches underestimated the built-up areas while SLEA extracted built-up areas properly. 


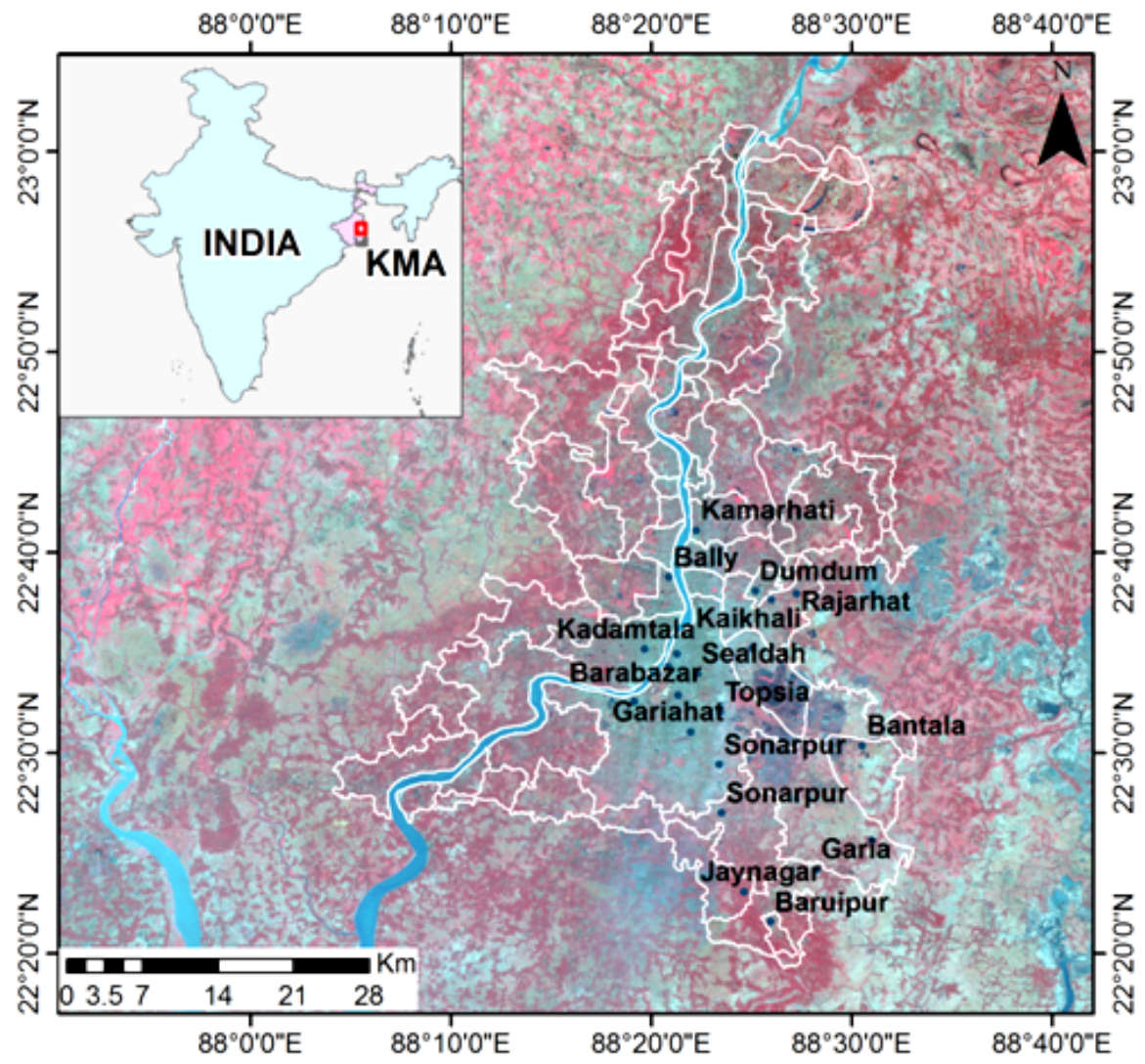

Fig. 1 The KMA in FCC of satellite image (2005).

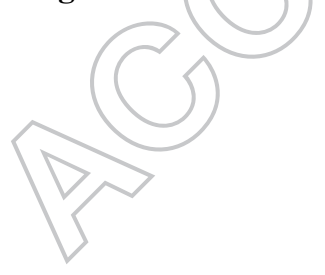




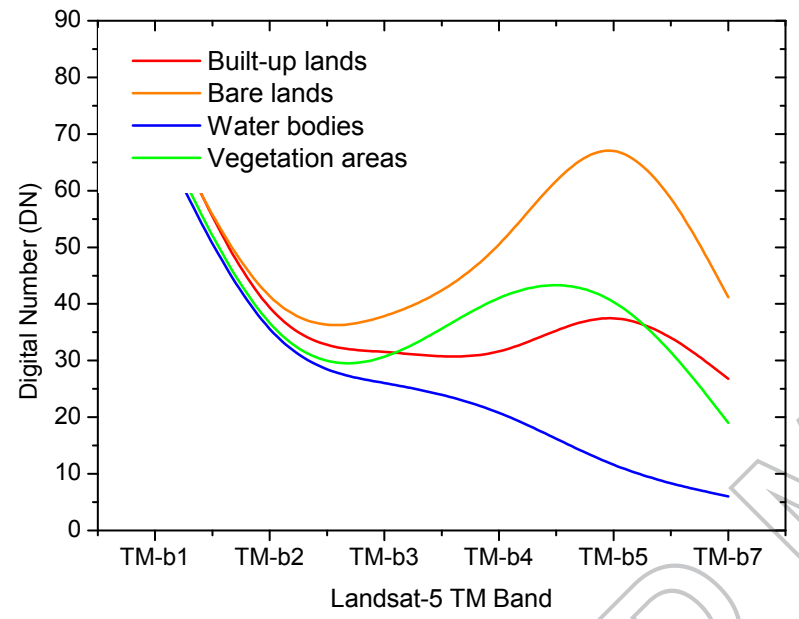

(a)

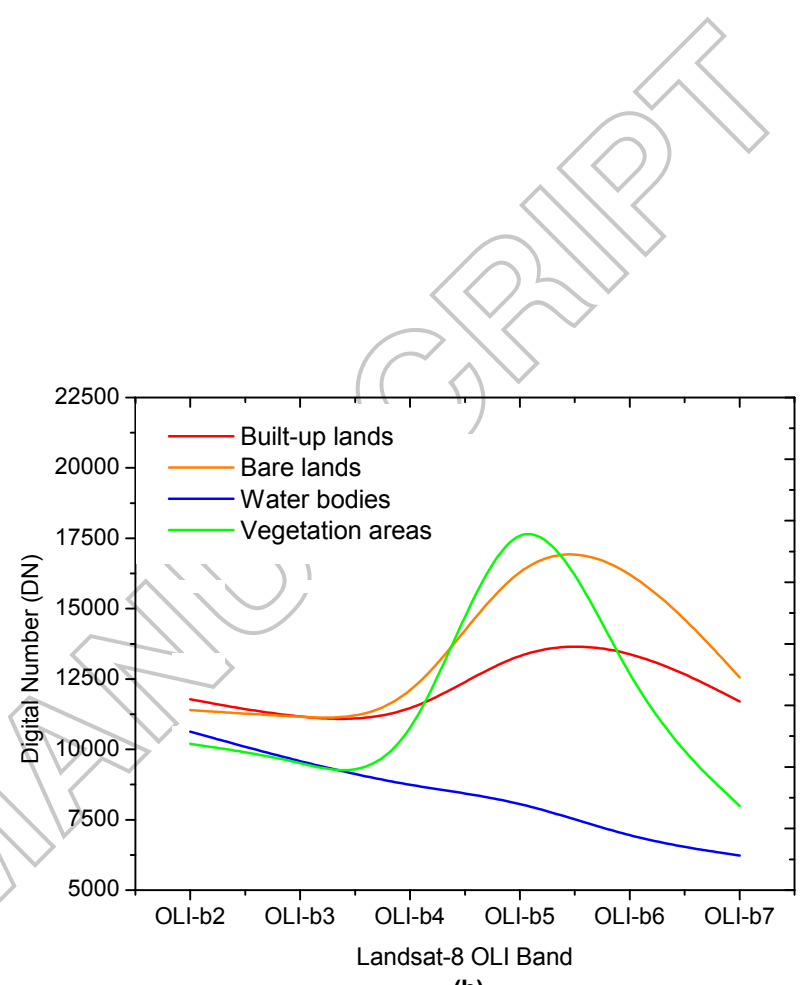

(b)

Fig. 2 Spectral signatures of built-up area, bare land, water body and vegetation area in (a) optical bands 1-5 and 7 of Landsat-5 TM and (b) optical bands 2-7 of Landsat-8 OLI. 
(a)

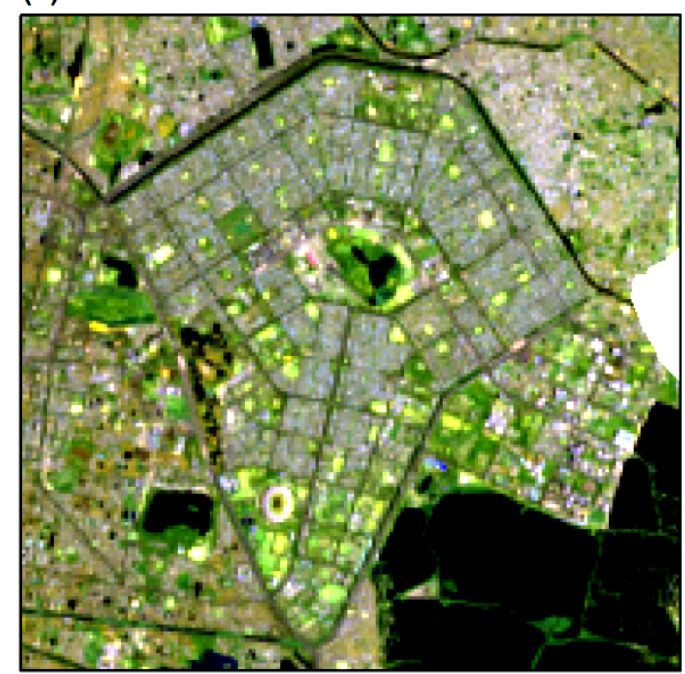

(b)

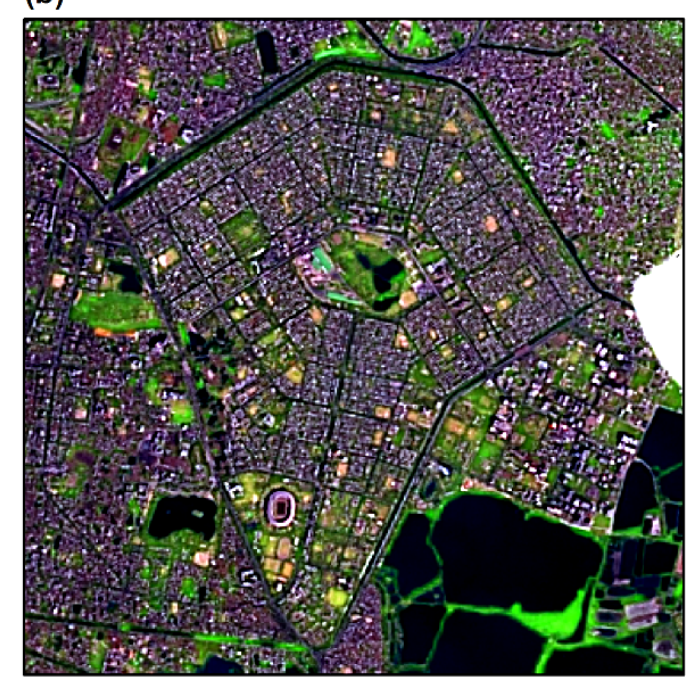

N

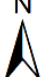

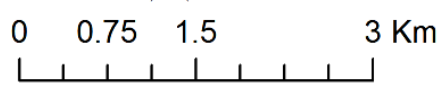

Fig. 3 Landsat-8 OLI in true colour composite (a) before resolution merging (30m spatial resolution) and (b) after resolution merging ( $15 \mathrm{~m}$ spatial resolution).This illustrates the visual difference between non-enhanced and spatially enhanced image, at the location of Salt Lake City, Kolkata. The increase in sharpness and level of detail in the enhanced image obtained by merging original low resolution band images with high resolution image (15m spatial resolution) using a bilinear 4-nearest neighbour algorithm.

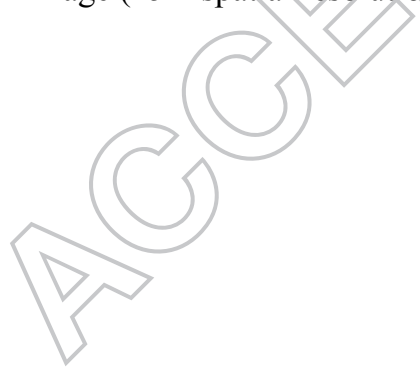




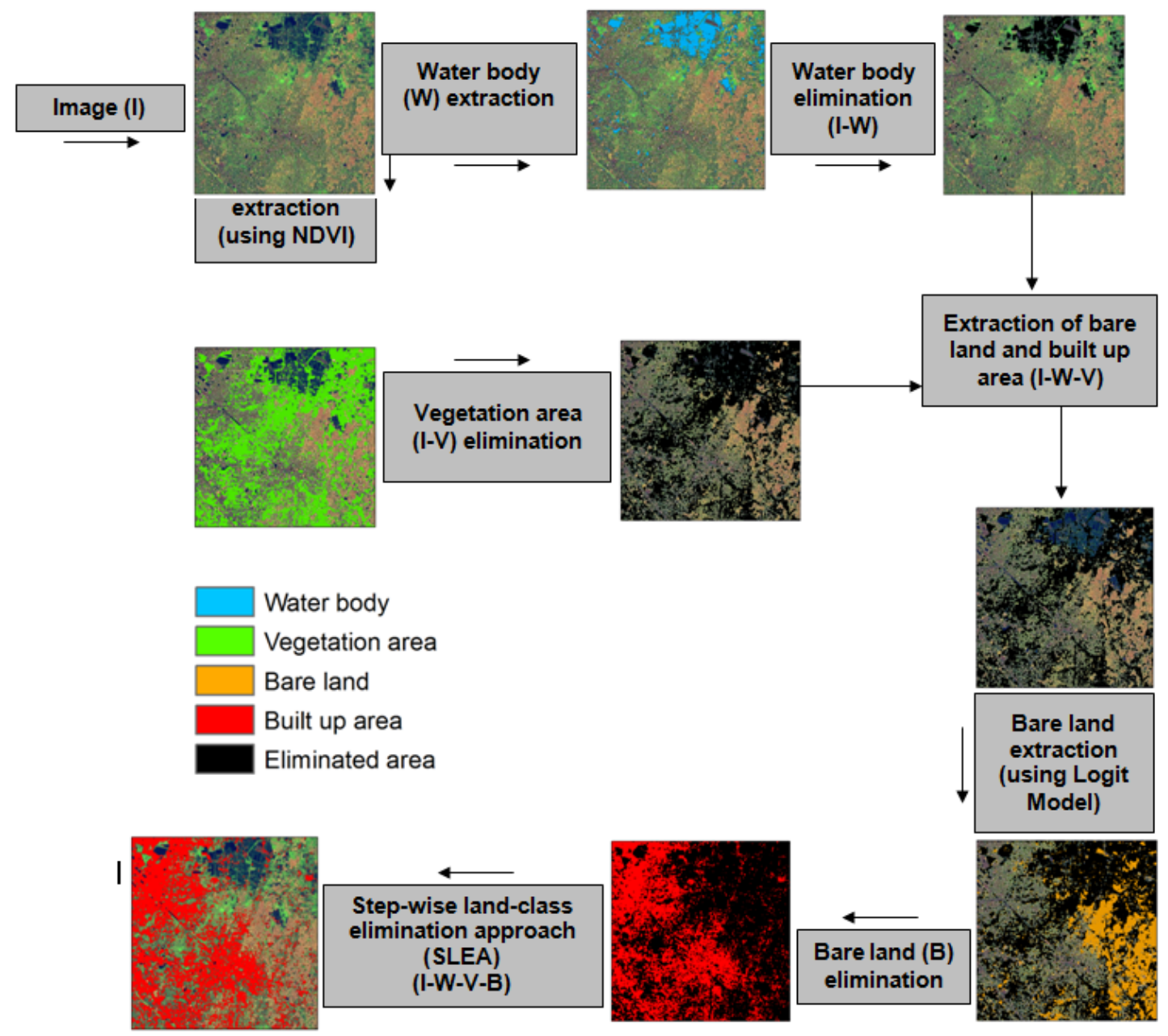

Fig. 4 Graphical flow chart for step wise elimination and extraction of water bodies, vegetation area, bare land and built up area from Landsat image. 


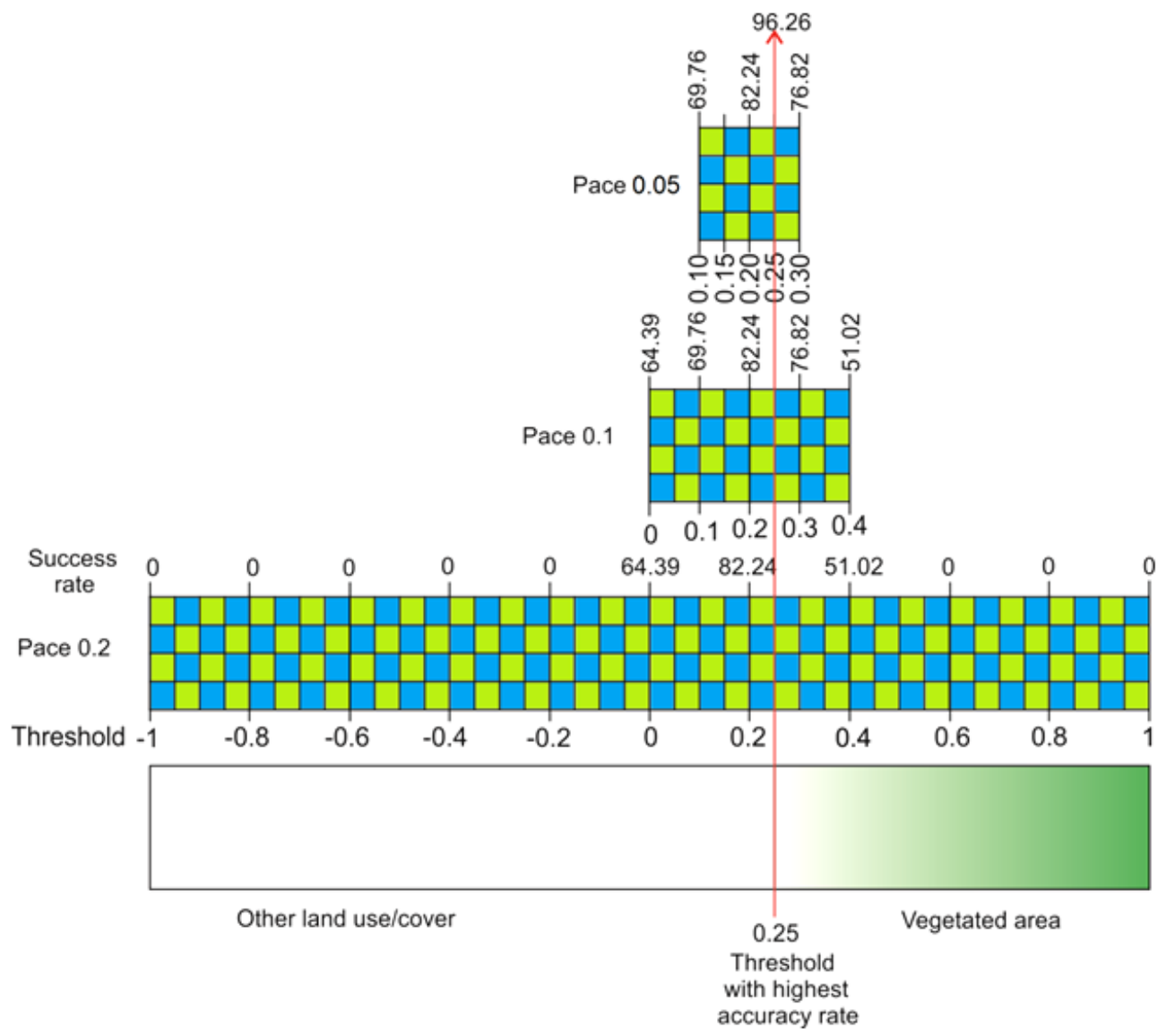

Fig. 5 Diagrammatic representation of DFPS process for determination of threshold DN value that segments the NDVI image into vegetated and other areas. Gradual narrowing of search range and shortening of pace range increase success rate of the search. Iterative searching finally determines the threshold value to be 0.25 with the highest success rate of 96.26 for this example of thresholding NDVI image derived from Landsat-5 TM of 2000. 

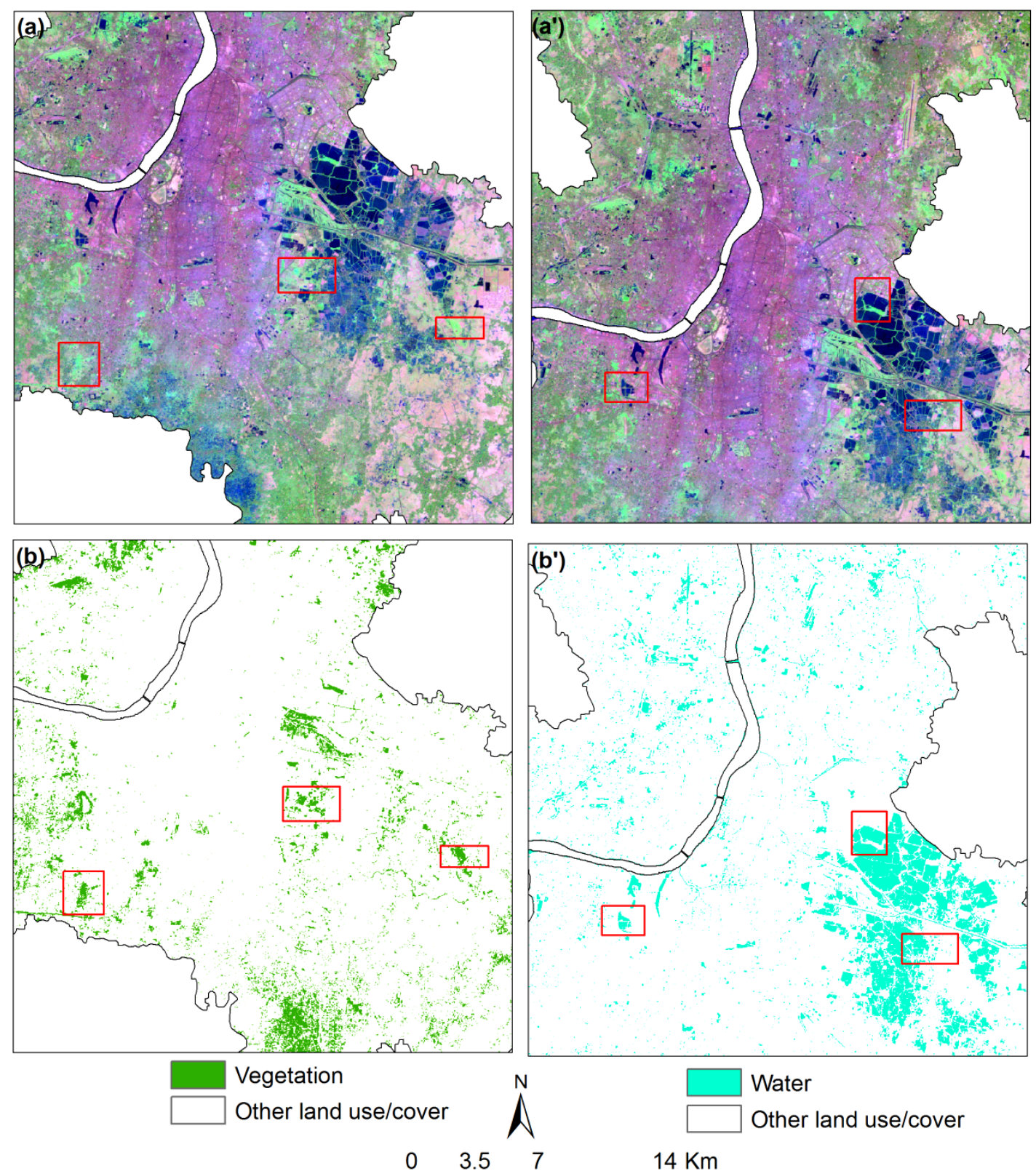

Water

Other land use/cover
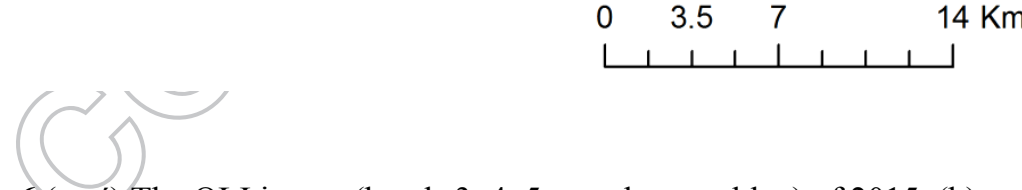

Fig. 6 (a-a) The OLI image (bands 3, 4, 5 as red-green-blue) of 2015, (b) output of vegetation area segmentation from NDVI image and $\left(b^{\prime}\right)$ output of water bodies segmentation from band 6 . Red rectangles in each panel show the sample areas where the DFPS approach applied to determine threshold values. 
(a)

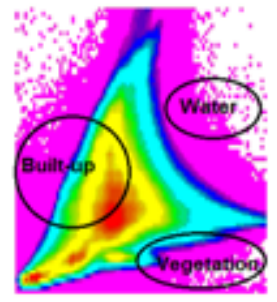

(b)

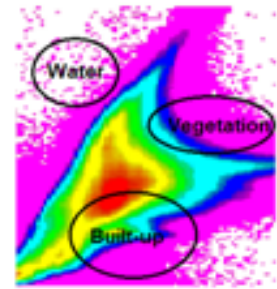

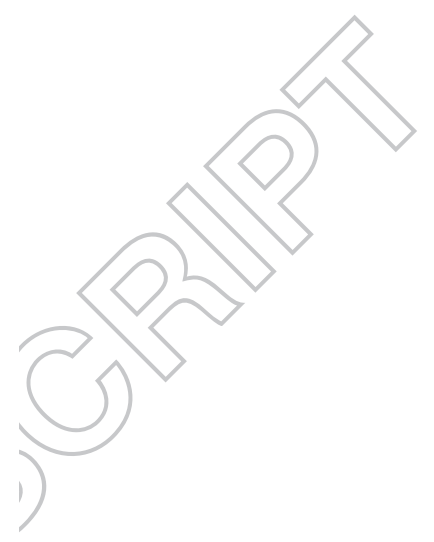

(c)

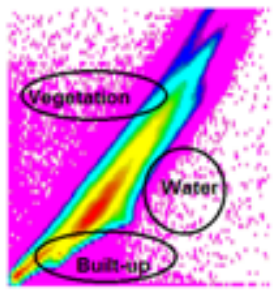

Fig. 7. Scatter plots showing the correlation between (a) band 4 (x-axis) and band 5 (y-axis) (b) band 4 (x-axis) and band 5 (y-axis) and (c) band 5 (x-axis) and band 6 (y-axis) for 2005; 2010 and 2015 respectively for (a-bTM data) and (c-OLI data). The Pearson's correlation value (R) of (a) 0.951, 0.942 and 0.961; (b) 0.962, 0.951 and 0.976 and (c) $0.957,0.964$ and 0.941 for water bodies, vegetation areas and built-up areas respectively. 


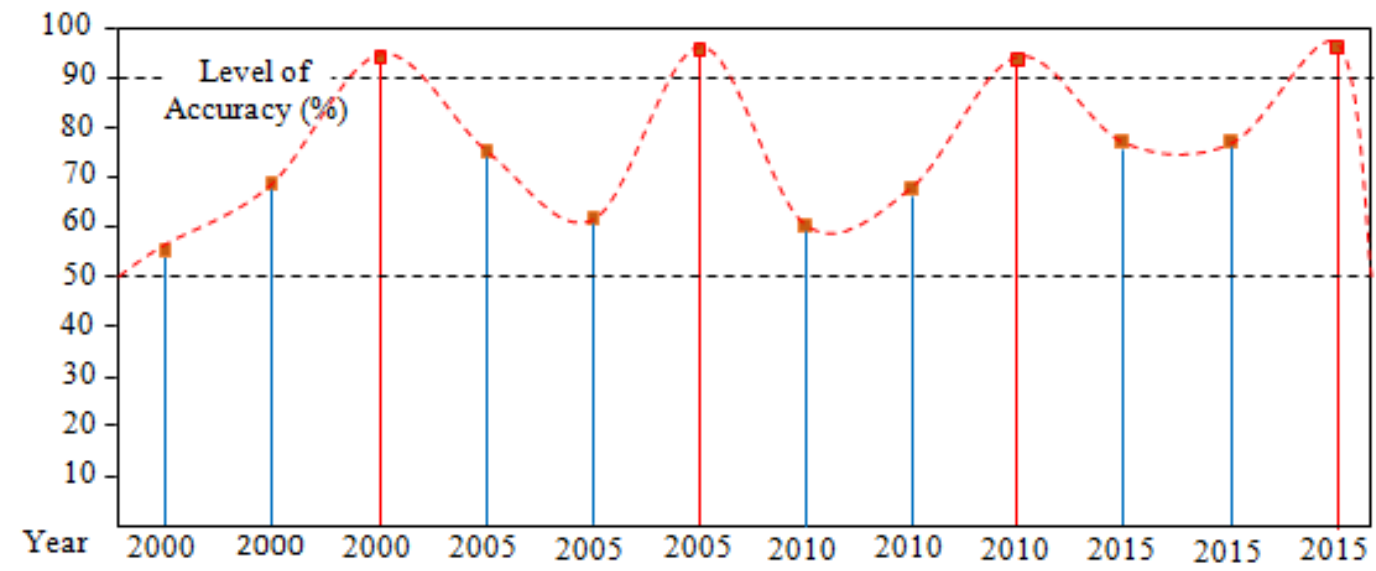

Model Fit-1 Fit-2 Fit-3 Fit- 1 Fit - 2 Fit- 3 Fit- 1 Fit - 2 Fit - 3 Fit - 1 Fit - 2 Fit - 3

$\begin{array}{cllllllllllll}\text { Consider } & 1 & 3 & \mathbf{2} & 1 & 2 & \mathbf{4} & 1 & 3 & \mathbf{3} & 1 & 2 & \mathbf{2} \\ \text { bands } & 3 & 2 & \mathbf{5} & 3 & 4 & \mathbf{5} & 3 & 2 & \mathbf{4} & 3 & 5 & \mathbf{5} \\ & 5 & 5 & 7 & 4 & 5 & 7 & 5 & 5 & \mathbf{5} & 5 & 7 & \mathbf{6}\end{array}$

Fig. 8 Fitting of Logit models for separating built-up areas from bare lands in the images (water bodies and vegetation areas eliminated): 2000, 2005, 2010 and 2015. Bold numerics denote image bands involved in the best fit model with highest accuracy. 

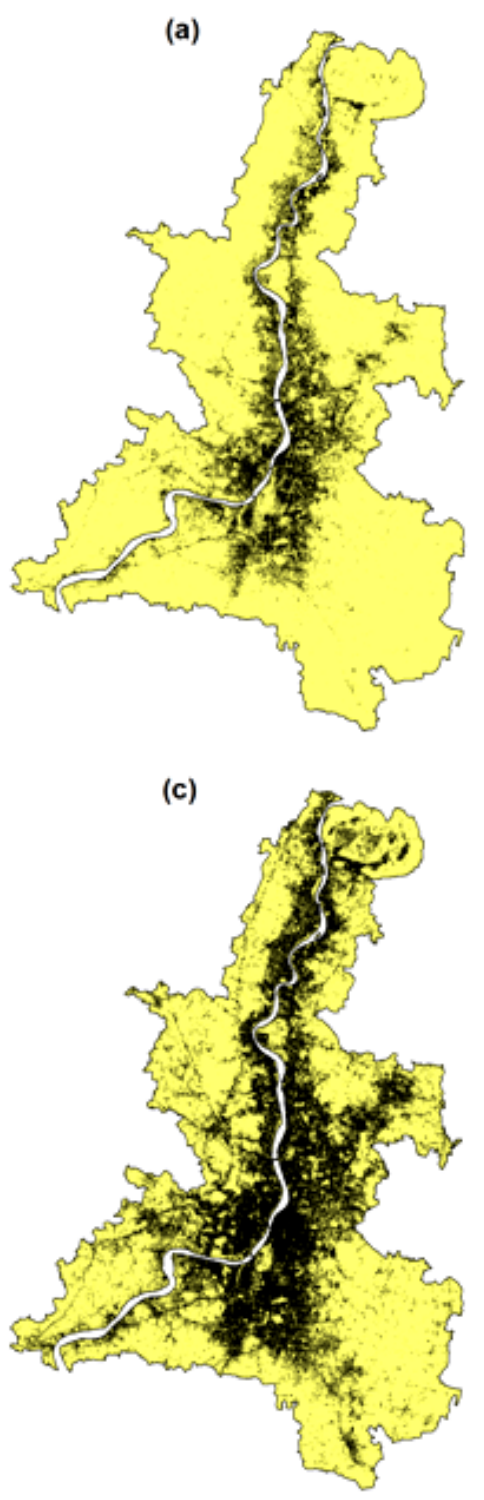

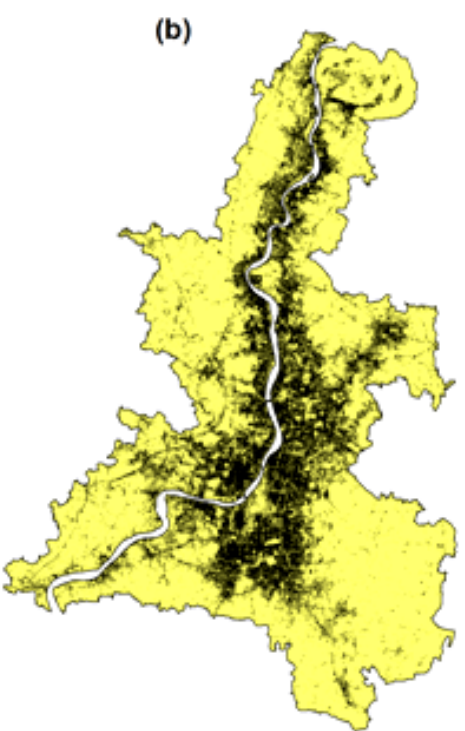

(d)

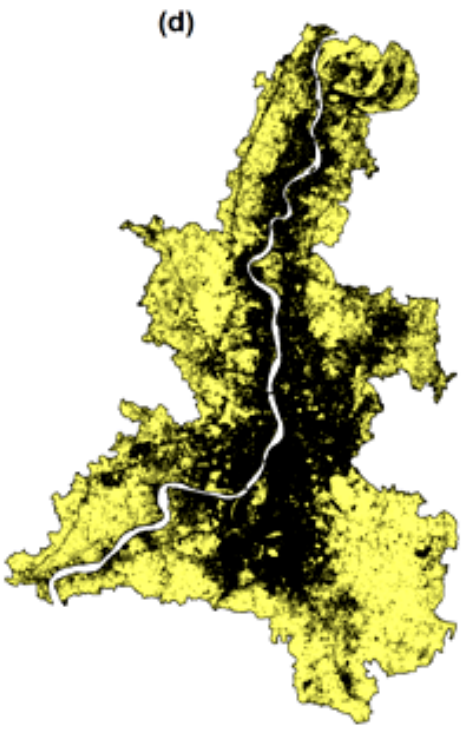

$9 \mathrm{Km}$

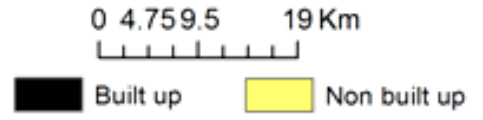

Fig. 9 Map of built-up areas in KMA derived from satellite images through application of SLEA for (a) 2000 (b) 2005 (c) 2010 and (d) 2015. 

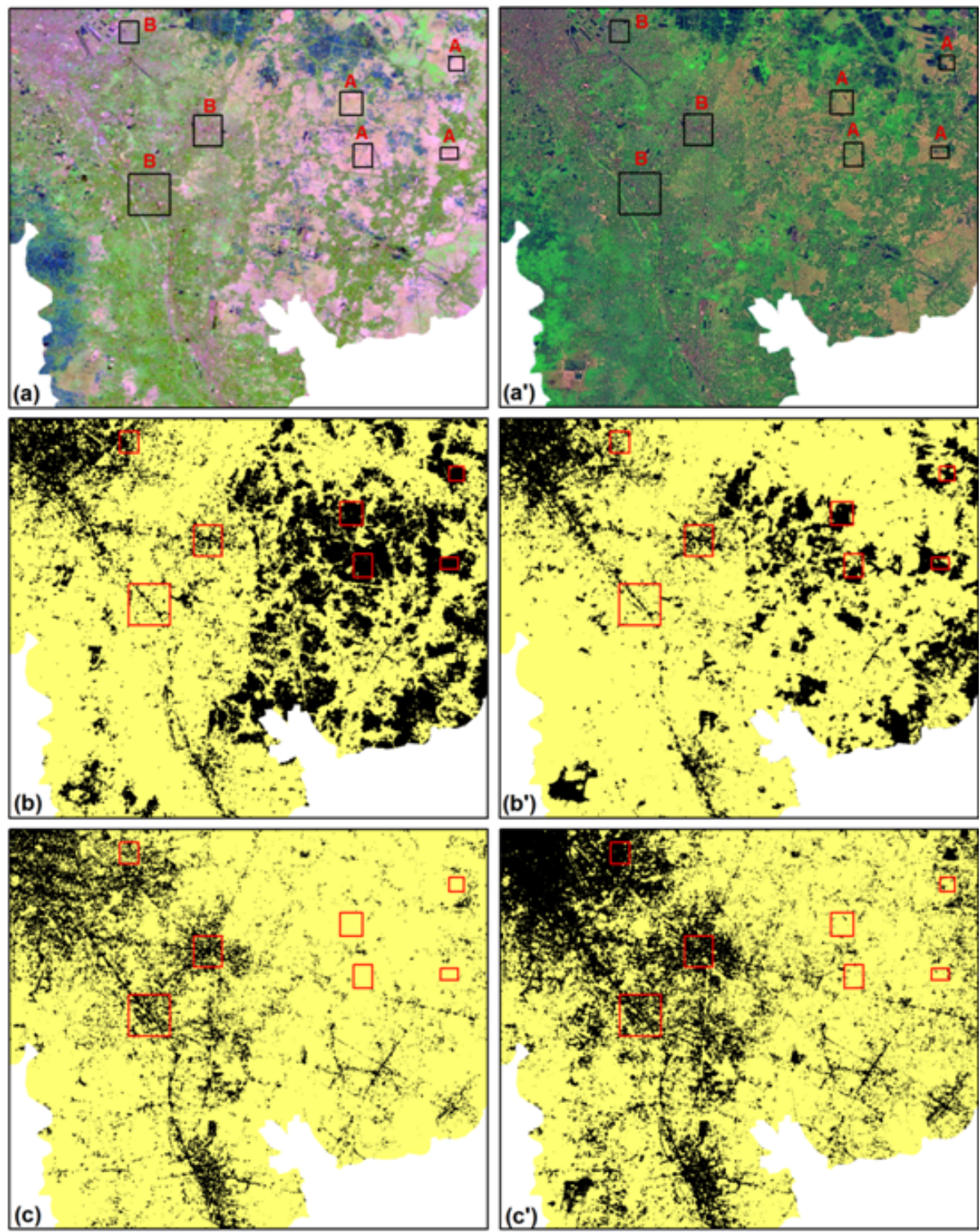

Built up area

Other land use/cover
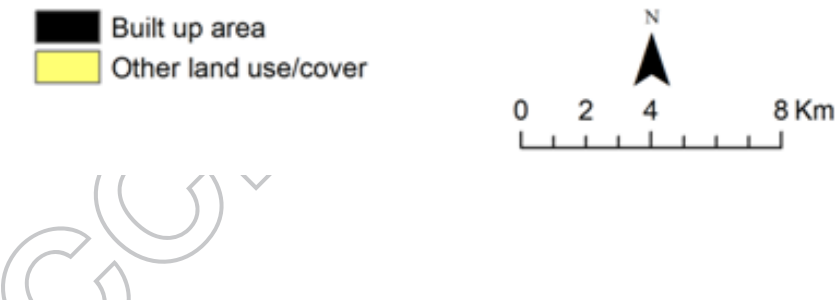

Fig. 10 Comparison of the results from the NDBI, BAEM and SLEA at sample locations, (a-a') Landsat-5 TM and Lansat-8 OLI of 2010 and 2015, respectively; (b-b') output from NDBI and BAEM respectively; (c-c') output from SLEA for TM and OLI, respectively. Red A rectangles in each panel show the places where the NDBI and BAEM approaches incorrectly extracted other land covers as built-up areas and red $\mathbf{B}$ rectangles show the places where the NDBI and BAEM approaches underestimated the built-up areas while SLEA extracted built-up areas properly. 
Table 1 Satellite data used in the study.

\begin{tabular}{|l|l|l|l|}
\hline Satellite & Date of acquisition & Path and row & Referencing system \\
\hline Landsat-5 TM & 12 January 2000 & $138 \& 44$ and $138 \& 45$ & UTM and WGS84 \\
\hline Landsat-5 TM & 10 January 2005 & $138 \& 44$ and $138 \& 45$ & UTM and WGS84 \\
\hline Landsat-5 TM & 20 May 2010 & $138 \& 44$ and $138 \& 45$ & UTM and WGS84 \\
\hline Landsat-8OLI and & 15 May 2015 & $138 \& 44$ & UTM and WGS84 \\
\hline
\end{tabular}

Table 2 An example of the DFPS for the determination of optimal threshold value of water pixels of the Landsat-8 OLI image of 2015

\begin{tabular}{|c|c|c|c|c|c|c|c|c|c|}
\hline \multicolumn{2}{|c|}{$\begin{array}{l}\text { Range: } \\
\text { 65535- } 535 \text { Pace } 5000\end{array}$} & \multicolumn{2}{|c|}{$\begin{array}{l}\text { Range: } \\
15535-5535 \mathrm{~Pa} \\
1000\end{array}$} & \multicolumn{2}{|c|}{$\begin{array}{l}\text { Range: } \\
8535 \text {-7535 Pace } 200\end{array}$} & \multicolumn{2}{|c|}{$\begin{array}{l}\text { Range: } \\
8535-8135 \text { Pace } 50\end{array}$} & \multicolumn{2}{|c|}{$\begin{array}{l}\text { Range: } \\
8435-8335 \text { Pace } 10\end{array}$} \\
\hline $\begin{array}{l}\text { Threshol } \\
\text { d }\end{array}$ & $\begin{array}{l}\text { Succes } \\
\text { s Rate }\end{array}$ & $\begin{array}{l}\text { Threshol } \\
\text { d }\end{array}$ & $\begin{array}{l}\text { Succes } \\
\text { s Rate }\end{array}$ & $\begin{array}{l}\text { Threshol } \\
\text { d }\end{array}$ & $\begin{array}{l}\text { Succes } \\
\text { s Rate }\end{array}$ & $\begin{array}{l}\text { Threshol } \\
\text { d }\end{array}$ & $\begin{array}{l}\text { Succes } \\
\text { s Rate }\end{array}$ & $\begin{array}{l}\text { Threshol } \\
\text { d }\end{array}$ & \begin{tabular}{|l} 
Succes \\
s Rate
\end{tabular} \\
\hline 65535 & 0 & 15535 & 3.59 & 8535 & 58.79 & 8535 & 58.79 & 8435 & 82.35 \\
\hline 60535 & 0 & 14535 & 5.38 & 8335 & 78.48 & 8485 & 72.65 & 8425 & 84.37 \\
\hline 55535 & 0 & 13535 & 11.28 & 8135 & 76.57 & 8435 & 82.35 & 8415 & 85.58 \\
\hline 50535 & 0 & 12535 & 16.27 & 7935 & 71.24 & 8385 & 84.27 & 8405 & 87.54 \\
\hline 45535 & 0 & 11535 & 22.59 & 7735 & 60.45 & 8335 & 78.48 & 8395 & 89.69 \\
\hline 40535 & 0 & 10535 & 26.25 & 7535 & 62.62 & 8285 & 79.56 & 8385 & 91.57 \\
\hline 35535 & 0 & 9535 & 32.14 & & & 8235 & 79.56 & 8375 & 94.59 \\
\hline $30535 \curvearrowright$ & 0 & 8535 & 58.79 & & & 8185 & 78.92 & 8365 & 95.37 \\
\hline 25535 & 0 & 7535 & 62.62 & & & 8135 & 76.57 & 8355 & 96.35 \\
\hline 20535 & 3.59 & 6535 & 37.54 & & & & & 8345 & $92 . .38$ \\
\hline 15535 & 26.25 & 5535 & 29.24 & & & & & 8335 & 88.48 \\
\hline 10535 & 29.24 & & & & & & & & \\
\hline 5535 & 0 & & & & & & & & \\
\hline 535 & 0 & & & & & & & & \\
\hline
\end{tabular}


Table 3 Summary results of the DFPS for determination optimum threshold values in eliminating the water and vegetation pixels and final extraction of built-up areas.

\begin{tabular}{|c|c|c|c|c|c|c|c|c|c|c|c|c|c|c|c|c|c|}
\hline \multirow[t]{2}{*}{ Year } & \multirow{2}{*}{$\begin{array}{l}\text { Target } \\
\text { land } \\
\text { class }\end{array}$} & \multicolumn{3}{|c|}{ First search } & \multicolumn{3}{|c|}{ Second search } & \multicolumn{3}{|c|}{ Third search } & \multicolumn{3}{|c|}{ Fourth search } & \multicolumn{3}{|c|}{ Fifth search } & \multirow[b]{2}{*}{$\begin{array}{l}\text { Opti } \\
\text { mu } \\
\text { m } \\
\text { thres } \\
\text { hold }\end{array}$} \\
\hline & & Range & Pace & $\begin{array}{l}\text { Maximu } \\
\mathrm{m} \\
\text { success } \\
\text { rate }\end{array}$ & \begin{tabular}{|l} 
Rang \\
$\mathrm{e}$
\end{tabular} & $\begin{array}{l}\mathrm{Pac} \\
\mathrm{e}\end{array}$ & $\begin{array}{l}\text { Maximu } \\
\mathrm{m} \\
\text { success } \\
\text { Rate }\end{array}$ & Range & $\begin{array}{l}\text { Pac } \\
\mathrm{e}\end{array}$ & $\begin{array}{l}\text { Maximum } \\
\text { success } \\
\text { Rate }\end{array}$ & Range & $\begin{array}{l}\text { Pac } \\
\mathrm{e}\end{array}$ & $\begin{array}{l}\text { Maxi } \\
\text { mum } \\
\text { succes } \\
\text { s rate }\end{array}$ & Range & Pace & $\begin{array}{l}\text { Maxi } \\
\text { mum } \\
\text { succe } \\
\text { ss rate }\end{array}$ & \\
\hline \multirow[t]{3}{*}{2000} & NDVI & $1--1$ & 0.20 & 72.36 & \begin{tabular}{|l|}
$0-$ \\
0.40
\end{tabular} & 0.10 & 82.93 & $\begin{array}{l}0.10- \\
0.30\end{array}$ & 0.05 & 96.26 & & & & & & & 0.25 \\
\hline & Water & $\begin{array}{l}255- \\
5\end{array}$ & 50 & 16.25 & $\begin{array}{l}105- \\
5\end{array}$ & 20 & 57.28 & $\begin{array}{l}45- \\
25 \\
\end{array}$ & 5 & 82.42 & $\begin{array}{l}45- \\
35\end{array}$ & 1 & 95.21 & & & & 37 \\
\hline & $\begin{array}{l}\text { Built- } \\
\text { up }\end{array}$ & $1-0$ & 0.10 & 95.83 & \begin{tabular}{|l|}
$0.05-$ \\
0.35 \\
\end{tabular} & 0.05 & 98.21 & & & & & & & & & & 0.45 \\
\hline \multirow[t]{3}{*}{2005} & NDVI & $1--1$ & 0.20 & 69.52 & \begin{tabular}{|l|}
$0-$ \\
0.40 \\
\end{tabular} & 0.10 & 86.65 & $\begin{array}{l}0.10- \\
0.30 \\
\end{array}$ & 0.05 & 95.83 & & & & & & & 0.25 \\
\hline & Water & $\begin{array}{l}255- \\
5\end{array}$ & 50 & 10.24 & \begin{tabular}{|l|}
$105-$ \\
5
\end{tabular} & 20 & 48.67 & $\begin{array}{l}45- \\
25 \\
\end{array}$ & 5 & 87.54 & $\begin{array}{l}40- \\
35\end{array}$ & & 94.52 & 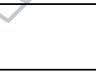 & & & 37 \\
\hline & $\begin{array}{l}\text { Built- } \\
\text { up }\end{array}$ & $1-0$ & 0.10 & 94.68 & $\begin{array}{l}0.50- \\
0.35 \\
\end{array}$ & 0.05 & 97.83 & & & & & & & & & & 0.45 \\
\hline \multirow[t]{3}{*}{2010} & NDVI & $1--1$ & 0.20 & 72.36 & \begin{tabular}{|l|}
$0-$ \\
0.40 \\
\end{tabular} & 0.10 & 88.35 & $\begin{array}{l}0.10- \\
0.30 \\
\end{array}$ & 0.05 & 97.53 & & & & & & & 0.25 \\
\hline & Water & $\begin{array}{l}255- \\
5 \\
\end{array}$ & 50 & 22.34 & $\begin{array}{l}105- \\
5 \\
\end{array}$ & 20 & 54.54 & $\begin{array}{l}45- \\
25 \\
\end{array}$ & 5 & 82.57 & & 1 & 96.24 & & & & 37 \\
\hline & $\begin{array}{l}\text { Built- } \\
\text { up }\end{array}$ & $1-0$ & 0.10 & 96.28 & $\begin{array}{ll}0.05- \\
0.35 \\
\end{array}$ & 0.05 & 97.85 & & & & & & & & & & 0.45 \\
\hline \multirow[t]{3}{*}{2015} & NDVI & $1--1$ & 0.20 & 46.25 & $\begin{array}{l}0- \\
0.4 \\
\end{array}$ & 0.10 & 46.25 & $\begin{array}{l}0.10- \\
0.30 \\
\end{array}$ & 0.05 & 68.24 & $\begin{array}{l}0.20- \\
0.25 \\
\end{array}$ & 0.01 & 97.56 & & & & 0.23 \\
\hline & Water & $\begin{array}{l}60689 \\
-689\end{array}$ & 5000 & 29.24 & $\begin{array}{l}1568 \\
9- \\
5689\end{array}$ & $\begin{array}{l}100 \\
0\end{array}$ & 62.62 & $\begin{array}{l}8689 \\
- \\
7689\end{array}$ & 200 & $\sqrt{38.48}^{78}$ & $\begin{array}{l}8489 \\
- \\
8289\end{array}$ & 25 & 84.27 & $\begin{array}{l}8489 \\
- \\
8439\end{array}$ & 5 & 96.35 & 8449 \\
\hline & $\begin{array}{l}\text { Built- } \\
\text { up }\end{array}$ & $1-0$ & 0.10 & 76.31 & \begin{tabular}{|l|}
$0.30-$ \\
0
\end{tabular} & 0.05 & 86.29 & $\begin{array}{l}0.10- \\
0\end{array}$ & 0.01 & 96.38 & & & & & & & 0.07 \\
\hline
\end{tabular}


Table 4 Co-efficient values of Logit model for built up area extraction.

\begin{tabular}{|c|c|c|c|c|c|c|c|c|}
\hline \multirow[t]{3}{*}{ Time } & \multirow{3}{*}{$\begin{array}{l}\text { Whole } \\
\text { intercept } \\
\text { value }(\alpha)\end{array}$} & \multicolumn{5}{|c|}{ Selected band } & & \\
\hline & & band 1 & band 2 & band 3 & band 4 & band 5 & band 6 & band 7 \\
\hline & & \multicolumn{7}{|c|}{ Intercept value $(\alpha)$} \\
\hline \multirow[t]{2}{*}{2000} & 10.80 & & & & -0.00 & -0.35 & & 0.34 \\
\hline & 13.05 & & -0.08 & & & -0.36 & & 0.35 \\
\hline \multirow[t]{2}{*}{2005} & 8.73 & & & & -0.02 & -0.25 & & 0.21 \\
\hline & 9.55 & & & & -0.16 & & & -0.10 \\
\hline \multirow[t]{2}{*}{2010} & 39.06 & 0.41 & & -1.07 & & -0.48 & 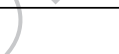 & 0.92 \\
\hline & 25.18 & & & -0.76 & -0.02 & -0.43 & & \\
\hline \multirow[t]{2}{*}{2015} & 29.06 & & & & & -0.52 & -0.27 & \\
\hline & 27.21 & & & & & -0.49 & 0.80 & \\
\hline
\end{tabular}


Table 5 Confusion matrix for NDBI, BAEM and SLEA

\begin{tabular}{|c|c|c|c|c|}
\hline Classified data & \multicolumn{4}{|l|}{ Reference data } \\
\hline NDBI & Non-built-up area & Built-up area & Classified total & User's accuracy (\%) \\
\hline Non-built-up area & 55 & 5 & 60 & 91.67 \\
\hline Built-up area & 44 & 196 & 240 & 81.67 \\
\hline Reference total & 99 & 201 & 300 & \\
\hline Producer's accuracy (\%) & 55.56 & 97.51 & & \\
\hline Overall accuracy NDBI (\%) & \multicolumn{4}{|l|}{83.67} \\
\hline BAEM & Non-built-up area & Built-up area & Classified total & User's accuracy $(\%)$ \\
\hline Non-built-up area & 101 & 3 & 104 & 97.11 \\
\hline Built-up area & 29 & 167 & 196 & 85.20 \\
\hline Reference total & 130 & 170 & 300 & \\
\hline Producer's accuracy (\%) & 77.69 & 98.24 & & \\
\hline Overall accuracy BAEM (\%) & \multicolumn{4}{|l|}{89.33} \\
\hline SLEA & Non-built-up area & Built-up area & Classified total & User's accuracy (\%) \\
\hline Non-built-up area & 106 & 2 & 108 & 98.14 \\
\hline Built-up area & 12 & 180 & 192 & 93.75 \\
\hline Reference total & 118 & 182 & 300 & \\
\hline Producer's accuracy (\%) & 89.83 & 98.90 & & \\
\hline Overall accuracy SLEA (\%) & \multicolumn{4}{|l|}{95.33} \\
\hline
\end{tabular}

Table 6 Summary of the accuracy assessment of the images derived by NDBI, BAEM and SLEA

\begin{tabular}{|l|l|l|l|l|}
\hline Method & Oyerall accuracy (\%) & Omission error (\%) & Commission error (\%) & k coefficient \\
\hline NDBI & 83.67 & 2.49 & 18.33 & 0.51 \\
\hline BAEM & 89.33 & 1.76 & 14.80 & 0.62 \\
\hline SLEA & 95.33 & 1.10 & 6.25 & 0.66 \\
\hline
\end{tabular}

